\title{
A Polymer Science Approach to Physico-Chemical Characterization and Processing of Pulse Seeds
}

\author{
Kelly A. Ross, Susan D. Arntfield and Stefan Cenkowski
}

Additional information is available at the end of the chapter

http://dx.doi.org/10.5772/46145

\section{Introduction}

A polymer science approach in the physico-chemical characterization of food systems has been highlighted in the literature as concepts of polymer science have been applied to understanding the effect of the glass transition on various food properties. The importance of the glass transition with respect to the processing and the stability of foods has long been recognized in food processing unit operations such as agglomeration, freezing, dehydration, flaking, sheeting, baking, and extrusion (Abbas et al., 2010; Campanella et al., 2002; Rhaman, 2006; Roos, 2010). However, the concept of the glass transition with respect to the processing of pulse seeds has been largely ignored. Successful value-added utilization of pulses, such as beans, for human consumption involves whole seed processing. Adequate hydration represents a significant requirement for processing of pulse products because only those pulse varieties for which water can consistently be absorbed to an acceptable level will be used in the processing of whole seed products and pulse based products (An et al., 2010). There is agreement in the literature that the seed coat is the structure that is primarily responsible for controlling water uptake, thus the seed coat is the principle barrier to water uptake (Arechavaleta-Medina \& Synder, 1981; DeSouza \& Marcos-Filho, 2001; Ma et al., 2004; Meyer et al., 2007; Ross et al., 2008; Zeng et al., 2005). The permeability of the seed coats of pulses have been studied extensively as poor hydration behaviour is commonly observed in pulse seeds. Although much research has been devoted to understanding the cause for differences in water uptake behaviour of pulse seeds, the approach has either been from a food science perspective in terms of characterizing the physical and chemical differences between impermeable and permeable seeds or from a botanical perspective concerned with defining the differences between the morphology and anatomy of permeable and impermeable seeds (Ross et al., 2008). A polymer science approach to understanding water uptake is necessary. An innovative explanation of water uptake behaviour in pulse seeds can be achieved by merging concepts from food science and 
polymer science. Key chemical differences in pulse seed coats have been studied with respect to their influence on water uptake behavior and the glass transition (Ross et al., 2010a). The effect of the glass transition temperature of seed coats on water uptake behaviour was reported by Ross et al. (2008). The mechanism of water uptake for pulse seeds possessing seed coats with a glass transition above ambient conditions was explained based on an analogy between a temperature driven glass transition $\left(\mathrm{T}_{\mathrm{g}}\right)$ and a solvent driven glass transition $(\mathrm{ag})$ presented in polymer science literature (Ross et al., 2010b). Alternatively, a hypothesis for the mechanism of water uptake in seeds possessing seed coats with a glass transition near ambient conditions implicating the time required to reach saturated surface concentration upon exposure to solvent was based on work reported in the field of polymer science (Ross et al., 2010b).

"Milling", by definition, is a process by which materials are reduced from a larger size to a smaller size (Wood \& Malcolmson, 2011). In the case of pulse processing there are several operations that can be characterized in this way, including: 1) dehulling which is defined as loosening and removal of the seed coat to produce polished seed (i.e. footballs); 2) splitting which is defined as loosening and cleavage of the two cotyledons to produce split seeds (i.e. splits); and 3) flour milling or grinding which is defined as reducing whole seed or cotyledons to flour (Wood \& Malcolmson, 2011). Variation in the ease of "milling" between the different pulse species primarily explains the wide variation in methodologies and pretreatments that have been developed to optimize yields (Wood \& Malcolmson, 2011). Dehulling is an important aspect of pulse processing as the dehulling efficiency (yield of dehulled seeds) is an important quality characteristic for pulse breeders, processors, and exporters as it ultimately dictates whether a dehulling operation is economically feasible (Wang et al., 2005; Ross et al., 2010c). The goal of dehulling is to completely remove the hull from pulse seeds while minimizing the production of powder, breaks, and in certain pulsessplit seeds (Wang et al., 2005). According to Wood \& Malcolmson (2011), the dehulling process without splitting is performed on pulses whose cotyledons are very tightly held together, such as lentil (Lens culinaris). In this case, a higher ratio of whole dehulled lentil seeds to split seeds is desired as whole dehulled lentil seeds are the most valuable fraction (Vandenberg \& Bruce, 2008). Red lentils account for the majority of world lentil production and trade and nearly $90 \%$ of red lentils are consumed as cooked split or whole seeds where the seed coat has been removed by dehulling. Since most red lentils are dehulled before consumption, dehulling efficiency (yield of dehulled seeds) of red lentil is very important (Ross et al., 2010c; Vandenberg \& Bruce, 2008; Wang, 2005). The rice industry cites breakage of rice kernels during milling/dehulling as one of its main problems (Iguaz et al., 2006). A large amount of work has been performed in the area of understanding the effect of drying temperature on rice milling quality (Cao et al., 2004; Cnossen et al., 2003; Cnossen \& Siebenmorgen, 2000; Iguaz et al., 2006). The concept of the glass transition has been used to explain rice kernel fissure formation during drying and subsequent breakage during milling of rice (Siebenmorgen et al., 2004). The effect of drying temperature on the handling quality of whole green lentil seeds in terms of seed breakage upon handling has been investigated (Tang et al., 1990), however little work has been done on the effect of drying temperature on 
the milling quality of red lentils. A better understanding of pulse seed breakage and splitting could be achieved by studying dehulling from a polymer science approach. Therefore, the hypothesis used to explain rice breakage was adopted to explain breakage and splitting in red lentils upon dehulling. Overall, this chapter focuses on: 1) the state of knowledge of the glass transition temperature in food systems; 2) the importance of pulses and how they are processed; 3 ) the state of knowledge of water uptake in pulse seeds; 4) defining the role of the $\mathrm{T}_{\mathrm{g}}$ with respect to water uptake in pulse seeds; and 5) defining the role of the $T_{g}$ with respect to dehulling of red lentils.

\section{The state of knowledge of the glass transition temperature in food systems}

\subsection{Definition of glass transition}

The glass transition theory from polymer science has been studied from a food science perspective since the pioneering work of Slade and Levine in the 1980's as many phenomena related to food processing and stability can be systematically explained by the concept of glass transition (Abbas et al., 2010; Campanella et al., 2002; Kumagai \& Kumaga, 2009; Lemeste et al., 2002; Rhaman, 2006; Roos, 2010). A material typically forms an amorphous glass if crystallisation is inhibited by steric hindrance and kinetic constraints (Norton, 1998). The glass transition is defined as a change in the state of an amorphous material from a solid/glassy-like to a liquid/rubbery-like state or vice versa (Figure 1) as the change of state (i.e. glass transition) exhibited by amorphous materials is a reversible transformation (Roos, 2010). The temperature range at which materials pass from a solid/glassy-like and liquid/rubbery-like structure or vice versa is considered the glass transition temperature $\left(\mathrm{T}_{\mathrm{g}}\right)$.

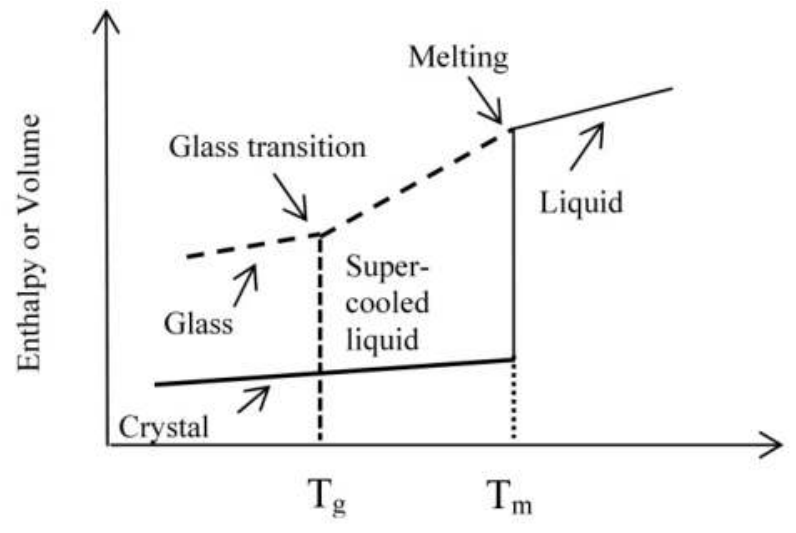

Temperature

Figure 1. Enthalpy or volume of various states of materials as affected by temperature (Adapted from Debenedetti \& Stillinger, 2001; Roos, 2010). $\mathrm{T}_{\mathrm{g}}$ is glass transition temperature; $\mathrm{T}_{\mathrm{m}}$ is melting temperature. 


\subsection{Theories of glass transition}

The glass transition does not exhibit latent heat and no temperature can be defined where the both the solid/glassy-like and liquid/rubbery-like states coexist (Roos, 2010). Both the solid/glassy and the liquid/rubbery states of amorphous materials, separated by the glass transition, are non-equilibrium states. Thus, materials in the glassy state are not completely stable and are described as existing in a metastable solid state (Roos, 2010; Slade \& Levine 1991). Rates of changes of amorphous materials are time-dependent and controlled by the ability of molecules within the material to respond to changes in their surroundings. Therefore, difficulties exist in understanding the properties of the non-equilibrium state of amorphous materials as it does not exhibit a characteristic order of molecular arrangement (Roos, 2010). Observations of the changes in thermodynamic properties (volume, enthalpy, entropy) and the kinetic nature of the glass formation have led to the development of several theories to explain the nature of the glass transition (Roos, 2010; Sperling 2006), which include: thermodynamic or entropic theories, free-volume theory, and kinetic theory. Thermodynamic or entropic theories state that the glass transition is a second order phase transition which is based on observed changes in the thermal expansion coefficient and heat capacity values that occur over the glass transition (Norton, 1998; Roos, 2010). These theories were devised by Gibbs (1956) and Gibbs \& DiMarzio (1958) based on the work of Flory (1953) and it was suggested the glass transition occurs when the relaxation time of the segmental motion of polymer chains approaches that of the experimental time scale (Roos, 1995). As shown in Figure 1, the enthalpy of a material changes differently with temperature in the glassy and rubbery-like states, indicating that the glass transition is associated with a change in heat capacity, however, no single temperature in glass transition measurements can be identified for the change in heat capacity (Roos, 2010). The thermodynamic approach has been criticized as it assumes the system is at equilibrium, yet Gibbs \& DiMarzio (1958) did note that although observed glass transitions are time-dependent, the real thermodynamic change in state occurs at infinitely long times (Roos, 2010). The free volume theory is rooted in the idea that if individual molecules are considered to be spheres in the glassy state, the unoccupied or free volume is reduced. For molecules to change their location or degree of motion, they must be able to move into the free volume (Roos, 2010). Creating a condition, such as increasing temperature or increasing moisture content, where the system temperature becomes higher than $\mathrm{T}_{\mathrm{g}}$, allows the system to transition from a glassy state into the rubbery state. This provides an increase in the free volume, allowing an increase in both rotational and translational molecular mobility. The fact that kinetically dependent processes such as viscosity or volume expansion (Norton, 1998) determine the free volume of a polymer system has led to the development of kinetic theories for explaining the nature of the glass transition. The kinetic theory of the glass transition considers the time dependent characteristics of the glass transition and time-dependent molecular relaxations that take place over the glass transition temperature range (Roos, 1995).

\subsection{Measurement of glass transition}

The glass transition has been typically determined by studying the changes in the thermal or rheological properties of a system, either as a function of sample temperature or 
composition, such as moisture content (Roos, 2010), as material properties including modulus, viscosity, volume, thermal expansion, and dielectric properties, exhibit a discontinuity around the glass transition. The glass transition associated with changes in rheological and dielectric material properties is attributed to mechanical and dielectric $\alpha$ relaxations, respectively. Therefore, glass transition and relaxations of amorphous materials may be measured with thermal, dielectric, mechanical, and spectroscopic techniques. Using thermal methods, such as differential scanning calorimetry (DSC), the glass transition appears as a change in enthalpy and volume in the measurement of thermodynamic properties such as heat capacity, whereas the appearance of translational mobility of molecules around the glass transition results in a frequency-dependent $\alpha$ relaxation manifested in changes in mechanical properties or permittivity, which are typically measured by mechanical and dielectric techniques, respectively, such as dynamic mechanical (thermal) analysis (DMA/DMTA) and dielectric thermal analysis (DEA/DETA), respectively. Spectroscopic techniques such as, infra-red and Fourier transform infra-red (IR/FTIR), Raman Electron Spin Resonance (ESR) and various NMR spectroscopy, have been used to provide information on chemical bonding and molecular mobility (Roos, 2010).

\subsection{Effect of glass transition on molecular mobility}

As noted, amorphous food materials are in a non-equilibrium state, which can be greatly affected during processing and storage conditions (Abbas et al., 2010; Campanella et al., 2002; Rhaman, 2006; Roos, 1991; Roos, 2010). The state of an amorphous material depends on its composition, temperature, and time. As temperature, relative humidity or moisture content increases, amorphous materials transform from the glassy state to the rubbery state, which reflects changes in molecular mobility and in mechanical and dielectric properties (Roos, 2010; Slade \& Levine 1991). The movement of the matrix molecules in a system is greatly reduced in the glassy state compared to the rubbery state. Although, mobility of small molecules does occur in glassy biomolecular systems via vibration and short-range rotational motions (Sperling, 2006), the enhanced stability of food systems in the glassy state have been attributed to reduced molecular mobility below $\mathrm{Tg}$ (Norton, 1998). The control of moisture content or water activity and temperature of glassy foods is of great importance as the concept of the glass transition helps to explain changes which occur during food processing and storage. Typical changes in amorphous food materials above the $T_{g}$ include stickiness, caking, collapse, and crystallization, textural changes such as softening and hardening, as well as chemical changes, such as enzymatic reactions and oxidation (Abbas et al., 2010; Li, 2010; Roos, 2010,). Furthermore textural changes, which are manifested as changes in mechanical properties, occurring over the glass transition, are characterized as a function of temperature, moisture content or water activity (Peleg, 1993; Roos, 2010). A state diagram, which reflects the relationship between $\mathrm{T}_{\mathrm{g}}$ and moisture content (or water activity) and temperature, is a valuable tool to manipulate both $\mathrm{T}_{\mathrm{g}}$ and material behavior under various storage and processing conditions (Roos 1993). Explicitly, a state diagram can be used to explain physical state changes of foods as a function of moisture content during water removal processes such as drying, baking, 
extrusion, evaporation, freezing, or water uptake processes such as agglomeration or tempering and flaking (Abbas et al., 2010; Campanella et al., 2002; Roos, 2010). Therefore application of the $\mathrm{T}_{\mathrm{g}}$ as a processing parameter in the food industry is immense and is of relevance to the pulse processing industry. Hydration represents a significant requirement for processing of pulse products. Optimization of the dehulling/milling quality of pulses requires definition of the relationship between drying conditions and $\mathrm{T}_{\mathrm{g}}$.

\subsection{Effect of water on the glass transition}

As noted, water is a key factor affecting the glass transition. The molecular weight of water is significantly lower than most food components, which lowers the local viscosity and enhances molecular motion (Ferry, 1980), thereby adding free volume to the system. Uptake of water by an amorphous solid system will cause "plasticization" and will result in a decrease in the glass transition temperature (Li, 2010). The process of water uptake involves two main processes: 1) adsorption, which is the interaction of water with surface solids; and 2) absorption, in which water penetrates the bulk solid structure (Li, 2010). Van der Waals interactions and chemical adsorption by chemical bonding are the two kinds of forces involved in adsorption. Water molecules first adsorb onto the surfaces of dry material to form a monolayer, which is subjected to both surface binding and diffusional forces. As more water molecules adhere to the surface, a water multilayer forms and diffusional forces exceed the binding forces. As such, water is absorbed into the bulk structure by pores and capillary spaces (Barbosa-Canovas, 1996; Li, 2010). The glass transition process occurs when water uptake changes from surface adsorption to bulk absorption (Li, 2010). Work noting the importance of the glass transition and water uptake was reported in Oksanen \& Zografi (1990) in which water vapor sorption isotherms of poly (vinylpyrrolidone) at various temperatures along with the measurement of $T_{g}$ as a function of water content were analysed. It was suggested that sufficient water uptake (moisture content), which was designated by the upward inflection of the isotherm, was needed to be attained to cause $\mathrm{T}_{\mathrm{g}}$ to be less than the experimental/environmental temperature and cause the polymer to transition into a rubbery state. At a higher temperature, less water was required to plasticise the sample because of the higher molecular mobility due to the higher temperature. This work is in agreement with the concept of critical water activity (aw) and moisture content (mc) set forth by Roos (1993) who noted that moisture content and aw can be considered as factors depressing $\mathrm{T}_{\mathrm{g}}$ to the environmental temperature, albeit whatever environment-i.e. processing conditions or storage conditions (Roos, 1993), thereby enhancing the molecular mobility of the system. Thus, critical aw or mc at which the glass transition occurs is a key parameter in predicting the behaviour of amorphous materials. Moreover, there is an analogy between the temperature driven glass transition $\left(\mathrm{T}_{\mathrm{g}}\right)$ and the solvent driven glass transition $(\mathrm{ag})$ in polymer science literature (Laschitsch et al. 1999; Leibler \& Sekimota 1993; Vrentas \& Vrentas 1991). At a constant temperature, a sorption curve of a polymeric glass may remain relatively flat until a certain solvent concentration is attained, after which the sorption curve displays a dramatic increase in solvent uptake (Laschitsch et al., 1999). This 
remarkable increase in solvent uptake can be considered to have occurred at the glass transition solvent activity $(\mathrm{ag})$ and consequently this increase in solvent uptake can be attributed to the plasticization of the polymer by the sorbed penetrant (Vrentas \& Vrentas 1991). Explicitly, the free volume of a polymer is affected by temperature in the same way as it is affected by the amount of plasticizer (e.g. water) present. This is a key concept in developing a hypothesis using the idea of glass transition to explain water uptake in pulse seeds and it will be revisited in a following section.

\section{Pulses and pulse products}

\subsection{Definition of pulses}

The family Leguminosae consists of more than 18000 species of plants and members of the family are often referred to as legumes or pulses, which are the second most important food source in the world after cereals (Tiwari et al., 2011). Pulses are defined as the dry, edible seeds of legume plants (Maskus, 2010), notably this definition excludes fresh (i.e. non-dried) green beans and green peas which are consumed and considered as vegetables along with a few oil-bearing seeds like groundnut (Arachis hypogaea) and soybean (Glycine max) which are grown primarily for edible oil extraction (Tiwari et al., 2011). The terms "legumes" and "pulses" are used interchangeably because all pulses are considered legumes but not all legumes are considered pulses (Tiwari et al., 2011). Geographic region will influence the types that of pulses that are grown. In Canada, the most commonly grown pulses include: field peas, beans, lentils and chickpeas. However, cowpea (black-eyed pea) is a recognized a key pulse crop in the Southern United States while mung bean is commonly used in China (Maskus, 2010). The Food Agriculure Organization (FAO) recognizes 11 primary pulses (Tiwari et al., 2011), which are presented in Table 1.

\subsection{Pulses: Utilization and processing}

It has long been known that pulse crops are a good source of protein, energy (carbohydrate), fibre and mircronutrients (vitamins and minerals) (Black et al., 1998a; 1998b) and interest in the utilization of pulses in the developed world is on the increase (Tiwari et al., 2011). Factors contributing to this include: their reported nutritional and health benefits, changes in consumer preferences, increasing demand for variety/balance, changes in demographics (age, racial diversity), rise in the incidence of food allergies and ongoing research on production and processing technologies (Boye et al., 2010). In fact, over the past four decades, world pulse production has increased by $49 \%$ from $40.8 \mathrm{Mt}$ in 1961 to $60.9 \mathrm{Mt}$ in 2008 (Watts, 2011). In 2008, dry beans accounted for one-third of global pulse production, followed by peas at $16 \%$ and chickpeas at $14 \%$. Cowpeas, pigeon peas, broad beans (or faba bean, horse bean), lentils, vetches and lupins accounted for the remaining third of production (Watts, 2011). Despite the increase global pulse production and the general trend toward the inclusion of health promoting foods into the diet, pulses are still considered to be an underutilized food source in Europe and the USA (Abu-Ghannam \& Gowen, 2011). 
Although, researchers have studied the development of whole seed products and use of pulse flours as ingredients in products conventionally formulated with non-pulse flour (Abu-Ghannam \& Gowen, 2011; Maskus, 2010) and efforts in this area are increasing.

\begin{tabular}{|c|c|}
\hline Pulse Class & Common Name (Scientific name) \\
\hline \begin{tabular}{|l|} 
Dry beans \\
\\
\end{tabular} & $\begin{array}{l}\text { Kidney bean, haricot bean, pinto bean, navy bean, black bean (Phaseolus } \\
\text { vulgaris); Lima bean, butter bean (Phaseolus lunatus); Azuki bean, adzuki bean } \\
\text { (Vigna anularis); Mung bean, black bean, golden gram, green gram (Vigna } \\
\text { radiata); Black gram, urad (Vigna mungo); Scarlett runner bean (Phaseolus } \\
\text { coccineus); Ricebean (Vigna umbellata); Moth bean (Vigna acontifolius); Tepary } \\
\text { bean (Phaseolus acutifolius) }\end{array}$ \\
\hline $\begin{array}{l}\text { Dry broad } \\
\text { beans }\end{array}$ & Horse bean (Vicia faba equina); Broad bean (Vicia faba); Field bean (Vicia faba) \\
\hline Dry peas & Garden pea (Pisum sativum var. sativum); Protein pea (Pisum sativum var. arvense) \\
\hline Chickpea & Garbanzo, Bengal gram (Cicer arietinum) \\
\hline $\begin{array}{l}\text { Dry } \\
\text { cowpea }\end{array}$ & Black-eyed pea, black-eye bean (Vigna unguiculata) \\
\hline Pigeon pea & Arhar/Toor, cajan pea, Congo bean (Cajanus cajan) \\
\hline Lentil & Green lentil, red lentil (Lens culinaris) \\
\hline $\begin{array}{l}\text { Bambara } \\
\text { groundnut }\end{array}$ & Earth pea (Vigna subterranea) \\
\hline Vetch & Common vetch (Vicia sativa) \\
\hline Lupins & Lupins (Lupinus spp.) \\
\hline $\begin{array}{l}\text { Minor } \\
\text { pulses }\end{array}$ & $\begin{array}{l}\text { Lablab, hyacinth bean (Lablab purpureus); Jack bean (Canavalia ensiformis); } \\
\text { Sword bean (Canavalia gladiata); Winged bean (Psophocarpus teragonolobus); } \\
\text { Velvet bean, cowitch (Mucuna pruriens var. utilis); Yam bean (Pachyrrizus erosus) }\end{array}$ \\
\hline
\end{tabular}

Table 1. Common Pulses (Adapted from Tiwari et al., 2011)

Some common forms of pulse based foods include: dry pulses (including whole, split, and/or dehulled); canned pulses; spouted pulses; fermented legumes, such as wadi and dhokla, which are chickpea based fermented products, and although technically not pulses but legumes, fermented soy bean products such as natto and chungkookjang which are short term fermented products and tauchu, miso, doenjang, and kochujang, which undergo long term fermentation. Value added pulse products such as micronized/infra-red heat treated pulses, quick-cook dehydrated pulses, extruded pulse products, roasted pulse seeds have been developed (Abu-Ghannam \& Gowen, 2011; Bellido et al., 2006; Maskus, 2010). Foods conventionally prepared with non-pulse flours have been formulated with pulses that have been milled into flours such as: pasta, noodles, tortillas, batters, breads, extruded snacks, flours, fried snacks, infant food, and other baked goods (Maskus, 2010). However an important aspect of all of these pulses products is the necessity for the inclusion of water to the whole pulse seed at some point during processing (An et al., 2010; Bellido et al., 2006). Commercial processing of dry peas and beans usually involves soaking the seeds overnight $(12-16 \mathrm{~h})$ in water at ambient temperature to encourage maximum water uptake (Thanos et al., 1998). 
Although water is a relatively inexpensive ingredient, time and costs associated with transporting hydrated seeds (typically canned) are relatively expensive factors. Quick-cook dehydrated pulses also require hydrothermal treatment (i.e. cooking in water) (Abu-Ghannam \& Gowen, 2011). Literature has indicated that tempering (raising the moisture content of the seeds by addition of small amounts of water to a predetermined moisture content is required pre-treatment step to produce an acceptable micronized whole pulse seed product (Bellido et al., 2006). Tempering has also been noted as an essential step in the processing of roasted pulse snacks (Abu-Ghannam \& Gowen, 2011). Furthermore, tempering of pulse seeds is an essential step in the milling and dehulling process as it improves yield of dehulled product material (i.e. dehulling efficiency), which is an important quality characteristic for pulse breeders, processors, and exporters, as it ultimately dictates whether a dehulling operation is economically feasible (Wood \& Malcolmson, 2011), Therefore, adequate hydration of whole pulse seeds is important to both the scientific and industrial communities for developing whole seed products and products formulated with pulse flours.

\section{The state of knowledge of water uptake in pulse seeds}

\subsection{Variations in water uptake behavior in pulse seeds}

The water uptake behavior of seeds from the Leguminoseae family, which includes pulse seeds, has been studied extensively due to variation in imbibition patterns commonly observed in seeds belonging to this family (Ragaswamy et al., 1985; Ross et al., 2008). Seeds that demonstrate a long period (i.e. lag) before appreciable water uptake can be considered poorly hydrating seeds while seed that demonstrate a rapid uptake in water (i.e. no lag) can be considered well hydrating seeds. For example, seeds like peas (yellow, green and Marrowfat), navy beans, kidney beans, chickpeas, lentils, and most soybeans have been noted to possess rapid water uptake and do not possess a lag period prior to imbibition (An et al., 2010; Abu-Ghannam \& McKenna, 1997; Hsu, 1983a; Hsu, 1983b; Liu et al., 2005; Meyer et al., 2007; Ross et al., 2008; Seyhan-Gurtas et al., 2001). However some pulses like pinto beans, black beans, dried green beans, red beans possess a significant lag period prior to the initiation of water uptake (Liu et al., 2005; Ross et al., 2008). Figure 2 shows a graph representing the water uptake behavior of well and poorly hydrating seeds.

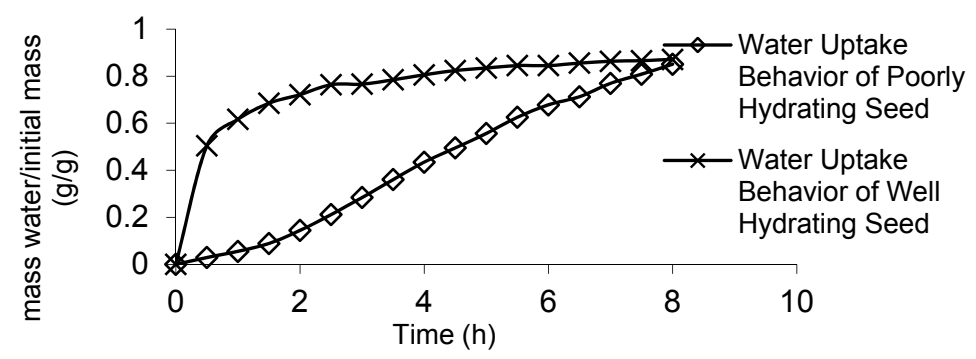

Figure 2. Water uptake behavior of well hydrating and poorly hydrating seeds 
It should be noted that the terms hard or stone seeds appear in food science and botanical literature. Hard or stone seeds are seeds that are impervious to water and remain hard even after cooking (Argel \& Parton, 1999). From a botanical perspective, hard seeds are defined as seeds which will not germinate, of which water imbibition is an integral step, even if subjected to conditions ideal for germination (DeSouza \& Marcos-Filho, 2001). From a biological perspective hardseededness occurs as a long term seed survival mechanism. The presence of hard seeds in agricultural seed lots are detrimental as they contribute to uneven seedling emergence which may reduce yields and delay harvest. Hardseededness from a crop production perspective can be broken via thermal, chemical, and physical treatments (Argel and Paton, 1999; DeSouza and Marcos-Filho, 2001). Moreover, hard seededness is undesirable for the food processing industry due to its negative effects on product quality (Ma et al., 2005). Therefore water uptake in legume seeds is an issue that is important to both the scientific and industrial communities and much research has been devoted to understanding the cause and ultimate control of hard seededness and shortening the lag time of poorly hydrating seeds (Arechavaleta-Medina \& Snyder, 1981; Marcbach and Mayer, 1974; Thanos et al., 1998; Zeng et al., 2005). A key point is that while both poorly hydrating seeds and hard/stone seeds exhibit a barrier to water uptake and do not take up water for hours, days or even longer-until dormancy is broken in the case of hard seeds, despite this long, variable lag before the start of imbibition, once water uptake begins the rate increases and the final amount of water absorbed is comparable to that of well hydrating seeds (Arechavaleta-Medina \& Snyder, 1981). Therefore, the time needed before appreciable water uptake upon is a key factor in defining water uptake behavior. The long time required to soak pulses/legumes is one of the negative attributes associated with processing pulses/legumes. Understanding the cause of lag time is essential for effectively processing pulse seeds and ensuring opportunities for development of new pulse products and knowledge can be gained from examining the literature studying characteristics of well hydrating seeds, poorly hydrating seeds and hard/stone seeds.

\subsection{Factors affecting water uptake}

There is agreement in the literature indicating that the seed coat of a seed is the principle factor which determines water uptake behavior (Arechavaleta-Medina and Synder, 1981; DeSouza \& Marcos-Filho, 2001; King \& Ashton 1985; Ma et al., 2004; Meyer et al., 2007; Ross et al., 2008; Zeng et al., 2005) in pulses/legumes. With the aim of understanding differences in seed permeability, the physical, morphological and chemical characteristics of the seed coat of many pulses/legumes seeds has been extensively studied. A review of the literature shows that seed permeability, with respect to seed coat structure, has been studied from a food science and a plant anatomy perspective (Ross et al., 2008). Work in food science has accounted for physical differences for variation in water uptake behavior of seeds while work in botany has investigated differences between the morphology and anatomy to understand differences in imbibition patterns of seeds. Seed coat thickness has been noted in the literature as a factor affecting water uptake. Seeds with thicker seed coats have been shown in the literature to have slower water uptake rates (King \& Ashton, 1985; Sefa-Dedeh 
\& Stanley, 1979). However it has been shown that certain varieties of cowpeas possessing thicker seed coats than other cowpea varieties exhibit faster water uptake than cowpeas with thinner seed coats (Sefa-Dedeh \& Stanley, 1979). Water uptake behavior cannot solely be linked to seed coat thickness. Seed size has also been linked to water uptake behavior (Arechavaleta-Medina and Synder, 1981; Hsu et al., 1983a; Seyhan-Gurtas et al., 2001). As water uptake is determined via mass uptake such that a smaller seed would exhibit a proportionally greater increase in water mass uptake than a larger seed if both were taking up water at the same rate. Therefore, a difference in size could account for different water uptake rates but it would not offer an explanation for different starting times of water uptake (i.e. lag times) (Arechavaleta-Medina \& Synder, 1981. Porosity of the seed coat has been implicated as a factor affecting water uptake behavior. Soybean seeds with porous seeds coats have been noted to be permeable while seeds with non-porous seeds coats are typically impermeable (DeSouza \& Marcos-Filho, 2001). It is noted that while soybeans are not termed pulse seeds due to their high oil content, they are legume seeds and discussion of their seed coat properties with respect to water uptake is relevant and applicable to the seed coats of pulse seeds. In the discipline of botany the morphology and anatomy of a seed coat have been studied with the aim of understanding water uptake in seeds. Two opinions regarding the role of the seed coat on water uptake have been noted. One is that the seed coat has specialized regions for water loss and uptake such as the hilum, micropyle, lens, and raphe (DeSouza \& Marcos-Filho, 2001) while the second opinion is that the whole seed coat is involved in water exchange (Zeng et al., 2005). Work by Ma et al. (2004) and Zeng et al. (2005) stated that the whole seed coat should be regarded as an integrated system responsible for water absorbing properties as the palisade layer, which develops from the outer epidermis of the seed coat, plays a significant role in water uptake. Moreover, the cuticle of the palisade layer has been implicated as the key factor that determines the permeability of the soybean seed coat (Ma et al., 2004). Impermeability of seeds has been attributed to differences in the seed coat structures such as contracted palisade cells and a thick cuticle (Rangaswamy \& Nandakumar, 1985).

Additionally, there are numerous reports in the literature citing chemical differences in the seed coats of seeds that imbibe water rapidly and those that exhibit delayed water uptake (Arechavaleta-Medina \& Snyder, 1981; Marbach \& Mayer, 1974; Marbach \& Mayer, 1975; Rangaswamy et al., 1985; Reyes-Moreno et al., 1994) however, no universal explanation has been reported. Phenolics substances may affect water uptake (Marbach \& Mayer, 1974; Marbach \& Mayer, 1975). Wild type pea species with naturally impermeable seed coats possessed high phenolic content while cultivated pea species had a low phenolic content (Marbach \& Mayer, 1974). Phenolics, particularly tannins, have been reported to be responsible for reduced water uptake in bean seeds (Sievwright \& Shipe, 1986). The seed coats of impermeable soybean seeds have been shown to contain high amounts of lignin (a complex polphenolic molecule) (DeSouza \& Marcos-Filho, 2001). The work of McDougall et al. (1996) indicated that soybean genotypes with high lignin content in the seed coat tend to have low seed coat permeability, while genotypes with low lignin content tended to have high seed coat permeability. However, the work of Mullin and Xu (2001) which studied the 
composition of soy bean seed coat and water uptake indicated that lignin content did not influence seed permeability. Instead, their work demonstrated a relationship between hemicellulose, primarily xylan, content and poor water uptake. However, it has been shown that pulse seeds with inherently fast water uptake without a lag time contained lower levels of total phenolics and of these phenolics, the majority were non-tannin phenolics, while pulse seeds with inherently slow water uptake possessing a lag time contained higher total phenolics content and of these phenolics, the majority were tannins. (Ross et al., 2010a). Furthermore, this work (Ross et al., 2010a) showed that pulse seeds that were processed with a simple hydrothermal treatment to improve water uptake experienced a decrease in total phenolics content. Future work studying the influence seed coat chemistry on water uptake should include: 1) a more specific approach with regards to determination of seed coat phenolics, 2) concurrent determination of xylan content, and 3) determination of the monomeric phenolic composition of lignin.

Research in botany and plant science has linked loss of lipids in the seed coat to create permeable seeds (Zeng et al., 2005) however, food science research has not focused on relating the lipid chemistry of the seed coat and water uptake. As literature from a botanical perspective has implicated the cuticle of the palisade layer as the key factor that determines the permeability of the seed coat (Ma et al., 2004; Rangaswamy \& Nandakumar, 1985; Zeng et al., 2005), the chemical properties of the cuticle have subsequently been characterized in this respect. The cuticular layer of the soybean has been implicated as a key factor in water uptake behavior, noting it was the site of the moisture barrier (Arechavaleta-Medina \& Snyder, 1981). The cuticle is hydrophobic and consists of an insoluble, polymeric and structural component and a complex mixture of lipids including cutin, suberin, and waxes with different fatty acid compositions. Cutin, an insoluble lipophilic matrix, constitutes the framework of the cuticle (Casado \& Heredia, 2001). Specifically, cutin is a high molecular weight polyester composed of various inter-esterified C16 and C18 hydroxyalkanoic acids. Structural and physicochemical studies on cutin have shown that cutin exhibits an amorphous structure. Rapidly hydrating seeds have been shown to possess seed coats containing cuticular waxes with a plasticized structure and altered hydrophobicity (Egerton-Warburton, 1998). It has been documented that well hydrating soybean seeds possessed seed coats with a cuticle lacking mid-chain hydroxylated fatty acids while the cuticle layer of seed coats from impermeable seeds contained a disproportionately high amount of hydroxylated fatty acids (Shao et al., 2007).

Zeng et al. (2005) hypothesized that the process of creating permeable legume seeds during growing conditions includes both physical and chemical changes in the lipids of the cuticle layer of seed coat. It was speculated that heat provided from the environment during growing conditions likely causes the polymeric structure of the lipids to change through a weakening of the hydrophobic interactions, rendering lipids vulnerable to degradations and as such, the presence of heat and water likely causes thermal degradation and hydrolysis of the lipids in the seed coat to free fatty acids (Zeng et al., 2005). It has been reported that the rate of water uptake of whole bean seeds could be increased by subjecting the whole bean seeds to a simple hydrothermal treatment while the application of dry heat did not significantly improve water 
uptake (Ross et al., 2008) which is in agreement with the work of Zeng et al. (2005). Hydrolysis of lipids in the seed coat to fatty acids, which requires water, likely contributed to the improved water uptake observed in seeds treated hydrothermally compared the hydration behavior seen in the unprocessed seeds and seeds subjected to dry heat only. Chemical changes in the seed coat as affected by hydrothermal processing in relation to water uptake were addressed along with identification of chemical differences between bean varieties with different water uptake profiles (i.e. bean varieties with a lag versus bean varieties with no lag). Chemical properties of the unprocessed seed coat from navy bean seeds (Galley variety-no lag) and pinto bean seeds (AC Ole variety-lag) were examined to explain differences in their rates of water uptake. Seeds that readily imbibed water presented lower levels of fatty acids. The seed coats of unprocessed pinto beans (AC Ole) exhibited a fatty acid content of $1.39 \mathrm{mg} / \mathrm{g}$ seed coat while the seed coats from unprocessed navy beans (Galley) presented $0.42 \mathrm{mg} / \mathrm{g}$ seed coat. Processed AC Ole seed coats displayed fatty acid levels up to 2.9 times lower than the unprocessed pinto bean seed coats. This work demonstrated a link between lower lipid content with enhanced water permeability. However it should be noted that the fatty acids identified and quantified in Ross et al. (2010a) were obtained from hydrolysis of the triglycerides present in the seed coat. Thus the amount of identified fatty acids present in the seed coat decreased and this was associated with a decrease in total lipids. Thus, although the amount of the identified fatty acids derived from the triglyceride lipids present in the seed coat decreased, it is possible that the amount of free fatty acids present in the seed coat increased. Future work in this area should include quantification of free fatty acids present in seed coats from seeds with different water uptake profiles.

Importantly, it has been stated that permeability of the seed coat may be affected by the mechanical properties of the cuticle (Ma et al., 2004; Zeng et al., 2005). The mechanical properties of a material are influenced by the polymers that are present in the material (i.e. their chemical composition, molecular arrangement, and interaction of the molecules) along with temperature and moisture content (Hoseney, 1994). As noted, the glass transition temperature $\left(\mathrm{T}_{\mathrm{g}}\right)$ is a polymer science concept that has been applied to food science research for studying the material properties of biopolymers (Brent et al., 1997; Perdon et al., 2000). The stability and mechanical properties of a material vary depending on whether the material is above or below the $\mathrm{T}_{\mathrm{g}}$ (Lin et al., 1991; Roos, 1995). With respect to material stability, the phase transition behavior of non-leguminous plant cuticles has been studied in relation to water loss as a second order phase transition was noted to occur at a temperature that coincided with a remarkable increase in the water permeability behavior of the plant cuticles (Casado \& Heredia, 2001; Eckl \& Gruler, 1980). The seed coat cuticle has been described as being functionally analogous to the cuticular layers in other organs of plants, such as leaves (Egerton-Warburton, 1998). This seems to imply that the $\mathrm{T}_{\mathrm{g}}$ of a seed coat might influence water uptake behavior.

\subsection{Relating the glass transition and water uptake behavior}

Except for the work of Ross et al. (2008), to our knowledge, there have been no reports in the literature explicitly linking the glass transition behavior of seed coats and water uptake. 
However, there is a large volume of literature indicating that dormant seeds reside in the glassy state (Tolstoguzov, 2000; Williams, 1995) as there is much agreement between the glass transition temperatures of seeds as a function of water content and their storage stability as a function of storage temperature and water content (Roos, 1995). The two main objectives of (Ross et al., 2008) were to measure the $\mathrm{T}_{\mathrm{g}}$ of the seed coat of different beans and peas and relate $T_{g}$ with water uptake behavior, and to utilize $T_{g}$ as a processing parameter and subject the seeds to processing conditions above and below the $T_{g}$ with the aim of altering the physico-chemical properties of the seed coat in order to modify the water uptake behavior. Adapted from Ross et al. (2008), Table 2 shows that the seed coats of the pea (Mozart yellow variety and Stratus green variety) and navy bean (Morden and Galley varieties) samples, which are described as well hydrating pulses not exhibiting a lag, have a $\mathrm{T}_{\mathrm{g}}$ near room temperature $\left(20-34^{\circ} \mathrm{C}\right)$ and the glass transition temperature range covers a relatively narrow $10^{\circ} \mathrm{C}$ range around the $\mathrm{Tg}$. The beans AC Ole (pinto), AC Pintoba (pinto), and CDC Jet (black), seeds which as described as poorly hydrating demonstrating a lag, exhibit a glass transition temperature relatively higher than room temperature ranging from 37 to $81^{\circ} \mathrm{C}$. Figure 3 shows the water uptake behavior of unprocessed/unmodified peas (Mozart and Stratus) and beans (Galley, Morden, AC Ole, AC Pintoba, and CDC Jet). The consequences of different glass transition temperatures on the water uptake behavior of seeds may also be inferred from Figure 3. The pulses with relatively fast water uptake (i.e. no lag before substantial water uptake) all have $\mathrm{T}_{\mathrm{g}}$ values relatively close to room temperature and a narrow $\mathrm{T}_{\mathrm{g}}$ range, while the relatively slowly hydrating samples (i.e. an appreciable lag before water uptake begins) have $\mathrm{T}_{\mathrm{g}}$ values greater than room temperature and a broader $\mathrm{T}_{\mathrm{g}}$ range. It was noted that the seed coats from samples with relatively faster hydration are thinner than the seed coats of the samples with slower hydration (Table 2). However, as previously discussed water uptake behavior is not solely linked to seed coat thickness.

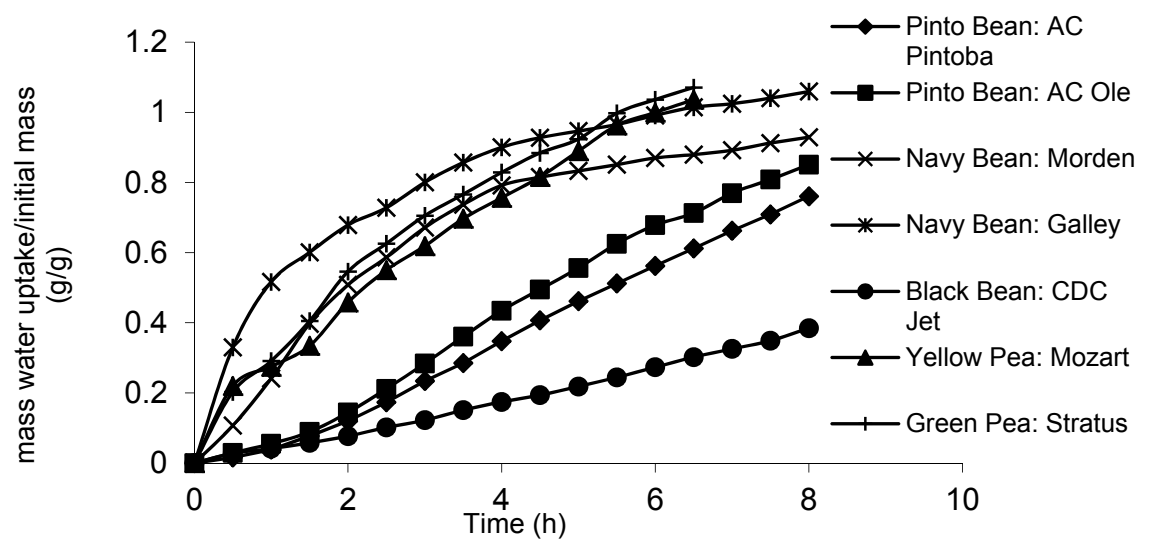

Figure 3. Water uptake behavior of native/unprocessed whole seed peas and beans (From Ross et al., 2008) 


\begin{tabular}{|c|c|c|c|c|}
\hline Pulse & $\begin{array}{c}\text { Seed Coat } \\
\text { Thickness } \\
(\mathbf{m m})\end{array}$ & $\begin{array}{c}\text { Seed Coat } \\
\text { Moisture Content } \\
\mathbf{( \% )}\end{array}$ & $\begin{array}{c}\mathbf{T}_{\mathbf{g}} \text { Range } \\
\left({ }^{\circ} \mathbf{C}\right)\end{array}$ & $\begin{array}{c}\mathbf{T}_{\mathbf{g}} \text { midpoint } \\
\left({ }^{\circ} \mathbf{C}\right)\end{array}$ \\
\hline $\begin{array}{c}\text { Mozart } \\
\text { (yellow pea) }\end{array}$ & 0.11 & 8.3 & $19-23$ & 21.4 \\
\hline $\begin{array}{c}\text { Stratus } \\
\text { (green pea) }\end{array}$ & 0.11 & 8.6 & $33-37$ & 33.3 \\
\hline $\begin{array}{c}\text { AC Pintoba } \\
\text { (pinto bean) }\end{array}$ & 0.23 & 9.7 & $43-65$ & $45.2=1.1$ \\
\hline $\begin{array}{c}\text { AC Ole } \\
\text { (pinto bean) }\end{array}$ & 0.18 & 9.6 & $33-66$ & 51.6 \\
\cline { 1 - 4 } $\begin{array}{c}\text { Processed AC Ole } \\
\text { (pinto bean): }\end{array}$ & 0.11 & 9.4 & $33-47$ & 37.7 \\
\hline $\begin{array}{c}\text { Galley } \\
\text { (navy bean) }\end{array}$ & 0.11 & 9.7 & $24-48$ & 26.2 \\
\hline $\begin{array}{c}\text { Morden } \\
\text { (navy bean) }\end{array}$ & 0.19 & 9.3 & $20-30$ & 22.2 \\
\hline $\begin{array}{c}\text { CDC Jet } \\
\text { (black bean) }\end{array}$ & $16 \%$ & 40.2 \\
\hline
\end{tabular}

${ }^{*}$ Beans were processed via tempering to $16 \%$ moisture content and subjected to cyclic heating $\left(60{ }^{\circ} \mathrm{C}\right)$ and cooling

Table 2. Moisture content, $\mathrm{T}_{\mathrm{g}}$ range and $\mathrm{T}_{\mathrm{g}}$ midpoint measurements for the seed coats of selected pulses at ambient environment (Adapted from Ross et al., 2008)

Research studying the water uptake behavior of different lentils, chickpeas and beans explicitly indicated that the mechanism responsible for the initial observed lag phase in water uptake was temperature sensitive (Seyhan-Gurtas et al., 2001). The effect of temperature on lessening the lag time observed in the water uptake of soybeans has also been reported (Arechavaleta-Medina \& Snyder, 1981). Moreover, a marked second order transition has been noted to occur at a temperature that coincides with a remarkable increase in the water permeability for non-leguminous plant cuticles (Matas et al. 2004; Matas et al. 2005; Schreiber \& Schonherr, 1990). The glass transition determines the rheological and mechanical properties of the biopolyester cutin and in turn determines mass transfer between the environment and plant cell (Matas et al. 2004; Matas et al. 2005). It follows that a similar situation may exist regarding the water uptake behavior of seeds. The $\mathrm{T}_{\mathrm{g}}$ of a seed coat might influence water uptake (Ross et al., 2008).

\subsubsection{Modifying water uptake behavior through processing}

In an attempt to modify the water uptake behavior of the bean samples exhibiting a lag prior to water uptake, a variety of processing regimes of cyclic heating $\left(45,60\right.$, and $\left.85{ }^{\circ} \mathrm{C}\right)$ and cooling to achieve a seed coat temperature of $7^{\circ} \mathrm{C}$ and static heating $\left(45,60,85^{\circ} \mathrm{C}\right)$ on non-tempered and tempered (13, 16, 24\% moisture content) seeds has been investigated (Ross et al., 2008). It was shown that all of the processing regimes performed on the non- 
tempered beans in their native state did not produce significantly improved water uptake behavior compared against the control/unprocessed seeds. AC Ole and AC Pintoba seeds that were tempered to $16 \%$ moisture content and subjected to a 45,60 , and $85{ }^{\circ} \mathrm{C}$ cyclic heating and cooling treatment exhibited a significant increase in their water uptake behavior compared against the control seeds (i.e. reduction in lag time water uptake). CDC Jet seeds that were tempered to $16 \%$ and subjected to cyclic heating at $85{ }^{\circ} \mathrm{C}$ and cooling showed significantly better water uptake than control seeds. The results seemed to indicate that both water and heat are required to induce the changes necessary to improve water uptake (Ross et al., 2008). Also, there were no significant differences between the water uptake behavior of the $16 \%$ tempered AC Ole and the water uptake behavior of the seeds that were heated at 45,60 , and $85{ }^{\circ} \mathrm{C}$. The $16 \%$ tempered AC Pintoba seeds subjected to 45 and $60{ }^{\circ} \mathrm{C}$ cyclic heating and cooling showed significantly better water uptake than the $16 \%$ tempered seeds subjected to $85{ }^{\circ} \mathrm{C}$ cyclic heating and cooling. This implied that the least aggressive and energy intensive treatment at $45{ }^{\circ} \mathrm{C}$ may be employed to elicit improved water uptake behavior. Interestingly, the $\mathrm{T}_{\mathrm{g}}$ of the seed coat of AC Ole $\left(51.6^{\circ} \mathrm{C}\right)$ was higher than the $\mathrm{T}_{\mathrm{g}}$ of the seed coat of AC Pintoba $\left(45.2^{\circ} \mathrm{C}\right)$. These results seem to indicate that the upper limit of the processing temperature which causes improved water uptake behavior may be influenced by the $\mathrm{T}_{\mathrm{g}}$ of the seed coat. Figure 4 illustrates the improvement that hydrothermal heat treatment has on the water uptake behavior of pulse seeds possessing a lag (Ross et al., 2008). The effect of a cooling step was also investigated in this work (Ross et al., 2008). The $16 \%$ tempered AC Ole and AC Pintoba seeds subjected to cyclic heating and cooling did not show significantly better water uptake compared against the $16 \%$ tempered seeds subjected to static heating. A cooling step was not required to cause improved water uptake behavior. Although, the presence of small cracks in the seed coat has been attributed to improved water uptake in seeds as literature has implicated the expansion and contraction experienced by the seed coat during growing conditions as a cause of stress gradients which ultimately creates cracks in the seed coat (Ma et al., 2004; Zeng et al., 2005).

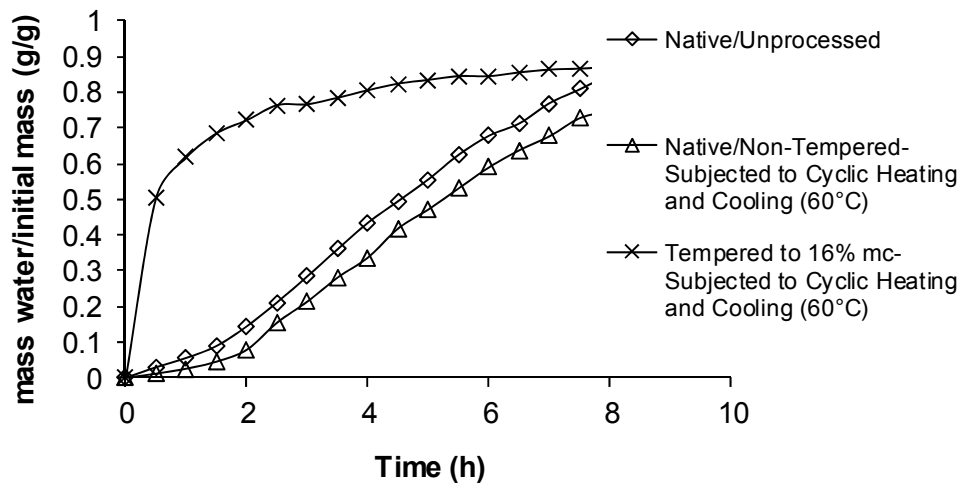

Figure 4. Water Uptake Behavior of Unprocessed and Whole Seeds (AC Ole, pinto bean) processed at $60^{\circ} \mathrm{C}$ with various conditions (Adapted from Ross et al., 2008). 
The glass transition temperature of the seed coat from AC Ole seeds that were tempered at $16 \%$ and subjected to cyclic heating at $60{ }^{\circ} \mathrm{C}$ and cooling to achieve a seed coat temperature of $7{ }^{\circ} \mathrm{C}$ was examined to determine whether physico-chemical changes of the seed coat were induced via processing and altered its $\mathrm{T}_{\mathrm{g}}$ (Ross et al., 2008). The measured $\mathrm{T}_{\mathrm{g}}$ for the seed coat of the $16 \%$ tempered $60{ }^{\circ} \mathrm{C}$ cyclic heated AC Ole seeds was $37.7 \pm 1.45{ }^{\circ} \mathrm{C}$ and the $\mathrm{Tg}$ range was $33-47^{\circ} \mathrm{C}$ (Table 2). The measured $\mathrm{T}_{\mathrm{g}}$ for the seed coat of unprocessed Ole was 51.6 $\pm 0.2{ }^{\circ} \mathrm{C}$ and the $\mathrm{T}_{\mathrm{g}}$ range was $33-66^{\circ} \mathrm{C}$ (Table 2). It appears that the $\mathrm{T}_{\mathrm{g}}$ range is less broad for the seed coat from the $16 \%$ tempered $60{ }^{\circ} \mathrm{C}$ cyclic heated seeds and the $\mathrm{T}_{\mathrm{g}}$ shifted to a lower temperature. The moisture content of the seed coat of the $16 \%$ tempered $60{ }^{\circ} \mathrm{C}$ cyclic heated AC Ole seeds was $9.4 \%$ (Table 2) and the moisture content of the seed coat of the unprocessed AC Ole seeds was $9.6 \%$ (Table 2) and therefore moisture content was not a factor in the decreased $\mathrm{T}_{\mathrm{g}}$ observed in the seed coat of the $16 \%$ tempered $60{ }^{\circ} \mathrm{C}$ cyclic heated AC Ole seeds. It appears that subjecting seed to water and heat alters the physico-chemical properties of the seeds coats (Ross et al., 2008).

\section{Linking the glass transition with water uptake in pulses: a polymer science approach}

\subsection{Modeling water uptake in pulse/legume seeds}

Water uptake by legume seeds has been discussed extensively in the literature. Many attempts have been made to shorten the required soaking time and other efforts have been focused on defining and predicting water absorption during soaking as a function of time and temperature (Abu-Ghannam \& McKenna 1997; Hung et al 1993; Sopade \& Obekpa 1990). Abu-Ghannam \& McKenna (1997) applied Peleg's (1988) two parameter nonexponential equation to model water absorption during the soaking of red kidney beans of both blanched and unblanched beans at 20,30, 40 and $60^{\circ} \mathrm{C}$. They indicated that Peleg's (1988) two parameter non-exponential equation described the hydration process of blanched beans more adequately than the unblanched beans as the unblanched beans exhibited a significant lag before water uptake began.

Also, there have been attempts to model water uptake and modes of water transfer in legumes using the laws of diffusion, however these models typically fail to describe water uptake data for pulses exhibiting a lag (Seyhan-Gurtas et al., 2001). Soaking at higher temperatures typically reduces/eliminates the lag observed in water uptake data which indicates a temperature sensitivity of the mechanism for the lag. Also, the importance of temperature on lag time and water uptake behavior of California white beans has been documented (Kon, 1979). A mathematical model based on Fick's diffusion, noting the influence of temperature on the concentration-dependent diffusivity of water into soybeans has been reported (Hsu 1983a; Hsu, 1983b]. Water uptake by dry beans was successfully modelled using diffusion theory along with a seed coat wetting theory (Liu et al., 2005). These works from food science literature (Hsu, 1983a; Hsu, 1983b; Liu et al., 2005) were key in proposing the effect of variable surface concentration at the seed coat and lag time in water uptake of legumes. Polymer science research has implicated (a) the degree of 
movement of the molecules at the polymer surface, and (b) surface concentration conditions, as being important variables affecting solvent/penetrant absorption (Fujita, 1961). Evidence has been provided showing that in rubbery polymers (i.e. polymers above their glass transition) a saturated surface concentration is attained instantaneously at the polymer surface and that many of the non-Fickian anomalies, such as sigmoid absorption curves, may be ascribed to the slow establishment of a saturated surface concentration condition at the surface of the sample below the glass transition (Richman \& Long, 1960). Above the glass transition temperature, solvent uptake by a polymer can be modelled with the following exponential equation (Kanamaru \& Hirata 1969):

$$
\frac{H(t)}{H_{e q}}=1-\exp (-k t)
$$

Where: $H(t)$ is the mass of the penetrant sorbed at a given time $(t), H_{e q}$ is the saturated amount of penetrant sorbed at equilibrium, $\mathrm{k}$ is the rate constant.

The water uptake profile generated by Eq. 1 has been shown to effectively model water uptake in seeds that do not possess a significant lag time (Meyer et al 2007). Alternatively, Nakano (1994a; 1994b) used an empirical equation to model water uptake in wood that exhibited sigmoid-type water uptake (i.e. possesses a lag time). The sigmoid-type water uptake behavior was attributed to a variable surface concentration during the initiation of water uptake and the importance of surface concentration conditions during water uptake was noted. The empirical equation used by Nakano $(1994 ; 1994 b)$ is similar in mathematical form to the empirical equation used by Peleg (1994a; 1994b) to model the mechanical changes in biopolymers at and around their glass transition. Peleg (1994a) indicated that many materials at certain conditions (i.e. temperature and moisture content) undergo considerable physical changes as a result of passing through the glass transition region. The glass transition affects not only mechanical properties of the material but many other physical properties especially those governed by internal molecular mobility. Near the glass transition, the relationship between the mechanical property and temperature (at constant moisture content) or that between the mechanical property and moisture content (at a constant temperature) has a characteristic sigmoidal shape. The mathematical form of the equation used by Peleg (1994a; 1994b) to provide a description of the mechanical behavior of biological materials around their glass transition was borrowed from Fermi's distribution function. The relationship between the mechanical property and temperature $(\mathrm{T})$ at constant moisture content described by Peleg (1994a; 1994b) was given by:

$$
Y(T)=\frac{Y_{S}}{1+\exp \left[\frac{\left(T-T_{\mathcal{C}}\right)}{a}\right]}
$$

Also, the relationship between mechanical property and moisture content at a constant temperature described by Peleg (1994a; 1994b) was given by: 


$$
Y(M)=\frac{Y_{S}}{1+\exp \left[\frac{\left(M-M_{\mathcal{C}}\right)}{a}\right]}
$$

Where: $\mathrm{Y}(\mathrm{T})$ and $\mathrm{Y}(\mathrm{M})$, in the above equations are the values of any mechanical property at the corresponding temperature $(\mathrm{T})$ or moisture content $(\mathrm{M}) . \mathrm{Y}_{\mathrm{s}}$ is the value of the mechanical property in the glassy or unplasticized state, and $T_{c}$ and $M_{c}$ are the characteristic temperature or moisture content, respectively. The parameters $T_{c}$ and $M_{c}$ occur at the inflection point on the curve and it occurs where there is a $50 \%$ reduction in the mechanical property. The empirical constant a, possesses the same units as the corresponding independent variable.

By tying these concepts together, Peleg's (1994a; 1994b) model of mechanical changes in biomaterials at and around their glass transition, was used to model the water uptake behavior of seeds that possess a lag time and an exponential equation of the form given by Kanamaru \& Hirata (1969) was used to model the water uptake behavior of seeds that do not possess a lag time (Ross et al., 2010b).

\subsubsection{Use of Peleg's mechanical model for characterizing water uptake in seeds exhibiting a lag phase}

Figures 3 and 4 display water uptake data for the seeds demonstrating a lag in their water uptake profile; the pinto beans (AC Ole) that were in their native (unprocessed) state, and those that were processed with cyclic heating $\left(60{ }^{\circ} \mathrm{C}\right)$ and cooling in a non-tempered (moisture content unaltered) state. This data was used in Peleg's (1994a; 1994b) equation, which describes mechanical changes in biopolymers at and around their glass transition, to model the water uptake. In doing so, the original water uptake data was expressed as a fraction of potential water sorption in order to present the data in a manner similar to Peleg's (1994b) report in which the data starts at an initially high value and falls as the independent variable increases (Ross et al., 2010b). This type of treatment is acceptable based on the symmetry of the curves. The equations are given as follows:

$$
m_{g}(t)=\frac{m(t)-m_{0}}{m_{0}}
$$

Where: $\mathrm{mg}_{\mathrm{g}}(\mathrm{t})$ is the mass of water sorbed at time $(\mathrm{t}), \mathrm{m}(\mathrm{t})$ is the mass at time $(\mathrm{t})$, and $\mathrm{m}_{0}$ is the original mass at time zero.

$$
\begin{gathered}
F_{h}(t)=\frac{m_{g}(t)}{m_{f}} \\
F_{\mathcal{U}}(t)=1-\left[\frac{m_{g}(t)}{m_{f}}\right]
\end{gathered}
$$


Where: $F_{h}(t)$ is the fraction of water sorbed at time $(t), F_{u}(t)$ is the fraction of potential water sorbed at time $(\mathrm{t})$, and $\mathrm{m} \mathrm{f}$ is the total mass of water sorbed at the equilibrium time point.

It was proposed that the amount of water sorbed could be considered the dependent variable, and soaking time at a constant temperature could be considered the independent variable. Their relationship was then described using a modified version of Eqs. 2 or 3. The modified version is given in Eq. 7, and it was explicitly noted that the independent variable is soaking time whereas the independent variable in Eqs. 2 and 3 is temperature or moisture content, respectively (Ross et al., 2010b).

$$
F_{u P}(t)=\frac{F_{S}}{1+\exp \left(\frac{\left(t-t_{c}\right.}{a}\right)}
$$

Where: $F_{u P}(t)$ is the fraction of potential water sorption at time $(t), F_{s}$ is the magnitude of this parameter in the glassy or unplasticized state (i.e. during the lag), $t_{c}$ is the characteristic time which occurs at the inflection point on the curve and it occurs where there is a $50 \%$ reduction in the fraction of the potential water sorption, $a$ is the empirical constant with the same units as time.

$\mathrm{F}_{\mathrm{s}}=1$ in the above equation because the value was taken at $\mathrm{t}=0$ (Ross et al., 2010b). Experimental water uptake data provided in Liu et al. (2005) for green beans soaked at 20 and $50{ }^{\circ} \mathrm{C}$ was also analysed with Eq. 7 (Ross et al., 2010) as these beans presented a lag in water uptake profiles. Figure 5 shows the experimental data and values generated with Eq. 7 for the native/unprocessed AC Ole pinto beans.

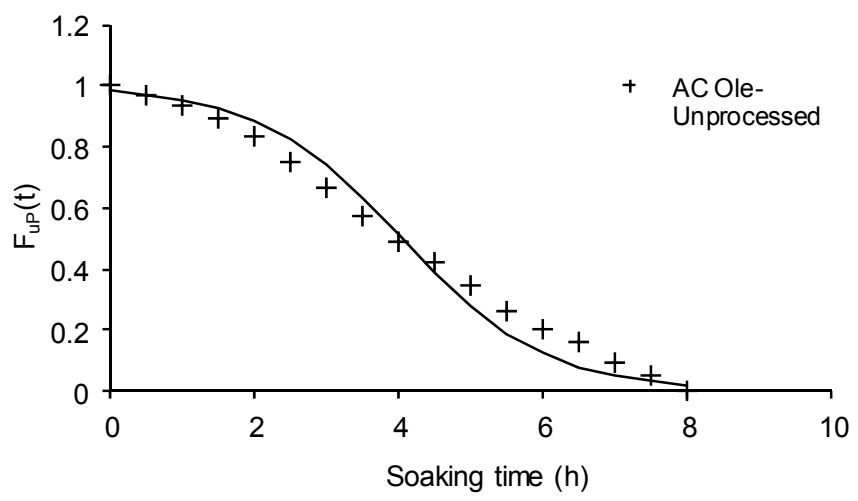

Figure 5. Fraction of potential water sorption as affected by soaking time fit into Peleg's mechanical model: Unprocessed AC Ole beans. Symbols indicate data points, line indicates prediction from model. (Ross et al., 2010b) 


\subsubsection{Use of an exponential model for characterizing water uptake in seeds exhibiting no lag phase}

Figures 3 and 4 also display water uptake data for the seeds that did not demonstrate a lag in their water uptake profile; the peas and AC Ole pinto beans tempered to $16 \%$ moisture content and treated with cyclic heating at $60{ }^{\circ} \mathrm{C}$ and cooling. This data was analysed with a modified version of the exponential equation presented by Kanamaru \& Hirata (1969) (i.e. Eq. 1). The data generated from the modified version of Eq. 1 were consequently expressed in a manner similar to the data obtained from Eq. 7 as the fraction of potential water sorption ( $\left.F_{u K}\right)$ at time (t) (Ross et al., 2010b). This type of treatment is acceptable based on the symmetry of the curves. The equations were given as follows:

$$
\begin{aligned}
& F_{u K}(t)=1-\left(\frac{m_{g}(t)}{m_{e q}}\right) \quad(\mathrm{a}) \\
& F_{u K}(t)=1-[1-\exp (-k t)] \quad(\mathrm{b})
\end{aligned}
$$

Where: $\mathrm{mg}(\mathrm{t})$ is the mass of the water sorbed at a given time $(\mathrm{t})$, meq is the amount of water sorbed at equilibrium or saturation, $\mathrm{k}$ is the rate constant.

Figure 6 shows the experimental data and values generated with Eq. $8 \mathrm{~b}$ for the beans tempered and treated with cyclic heating at $60{ }^{\circ} \mathrm{C}$. Table 3 provides a summary of the equations and constants used to model the data for all of the seed types along with the duration of lag time noted from respective water uptake curves, for the unprocessed AC Ole seeds, untempered processed AC Ole seeds, green beans soaked at $20^{\circ} \mathrm{C}$ and green beans soaked at $50^{\circ} \mathrm{C}$ from the work of Lui et al. (2005) and Ross et al. (2010b). The values obtained with Peleg's mechanical model (Eq. 7) for all of the samples exhibiting a lag agree well with the experimental data: the $\mathrm{R}^{2}$ values corresponding to Eq. 7 are all greater than 0.993 .

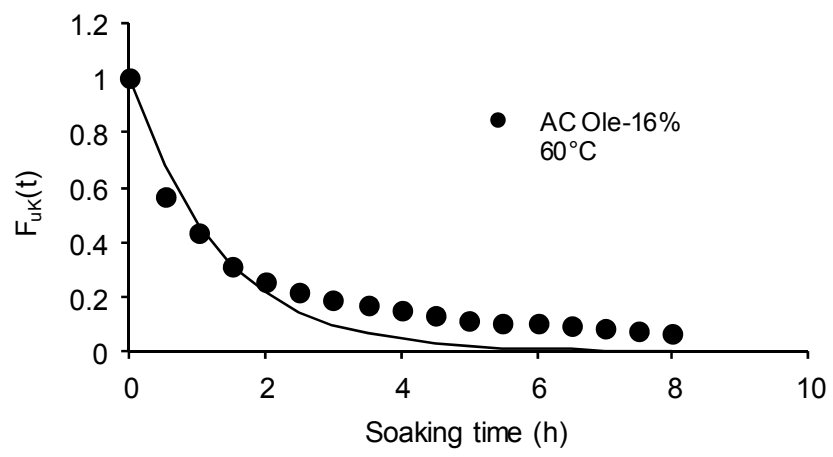

Figure 6. Fraction of potential water sorption as affected by soaking time fit into Kanamaru \& Hirata's sorption model: $16 \%$ tempered, $60^{\circ} \mathrm{C}$ cyclic heated and cooled AC Ole beans. Symbols indicate data points, line indicates prediction from model. (Ross et al., 2010b) 


\begin{tabular}{|c|c|c|c|c|c|}
\hline \multirow{2}{*}{ Material } & \multirow{2}{*}{ Lag Time (h) } & \multirow{2}{*}{ Equation } & \multicolumn{2}{|c|}{ Peleg constants } & \multirow{2}{*}{$\mathbf{R}^{2}$} \\
\hline & & & $\mathbf{t}_{\mathrm{c}}$ & $\mathbf{A}$ & \\
\hline AC Ole: Unprocessed & 2 & 7 & 4.2 & 0.854 & 0.993 \\
\hline $\begin{array}{c}\text { AC Ole: Non-tempered, } 60^{\circ} \mathrm{C} \\
\text { heat treatment }\end{array}$ & 2 & 7 & 4 & 1.049 & 0.997 \\
\hline $\begin{array}{c}\text { Green Bean: soaking water } \\
20^{\circ} \mathrm{C} \text { (Lui et al., 2005) }\end{array}$ & 5 & 7 & 7.2 & 1.46 & 0.997 \\
\hline \multirow[t]{3}{*}{$\begin{array}{c}\text { Green Bean: soaking water } \\
50^{\circ} \mathrm{C} \text { (Lui et al., 2005) }\end{array}$} & 0.5 & 7 & 1.8 & 0.429 & 0.998 \\
\hline & & & \multicolumn{2}{|c|}{$\begin{array}{c}\text { Kanamaru \& Hirata } \\
\text { constant }\end{array}$} & \\
\hline & & & \multicolumn{2}{|c|}{$\mathbf{K}$} & \\
\hline $\begin{array}{c}\text { AC Ole: tempered to } \\
\text { moisture content } 16 \%, 60^{\circ} \mathrm{C} \\
\text { heat treatment }\end{array}$ & na & $8 b$ & \multicolumn{2}{|c|}{0.769} & 0.989 \\
\hline Pea: Mozart & na & $8 \mathrm{~b}$ & \multicolumn{2}{|c|}{0.276} & 0.992 \\
\hline Pea: Stratus & na & $8 \mathrm{~b}$ & \multicolumn{2}{|c|}{0.302} & 0.998 \\
\hline
\end{tabular}

na=not applicable

Table 3. Parameters used to describe water uptake behaviour (Adapted from Ross et al., 2010b)

The values generated by the exponential equation $(8 b)$ were in good agreement with the experimental values of the unprocessed peas and beans tempered and treated with cyclic heating at $60{ }^{\circ} \mathrm{C}$ and cooling. The lowest $\mathrm{R}^{2}$ value corresponding to $\mathrm{Eq} 8 \mathrm{~b}$. is 0.989 . Therefore, fitting the experimental water uptake data with these equations provided evidence that the glass transition temperature of the seed coat is an important factor in the mechanism of water uptake in seeds. The seeds that possessed a lag time were well represented by Eq. 7, which was based on Peleg's (1994a; 1994b) model describing changes near the glass transition, while seeds that did not possess a lag time were well characterized by Eq. 8 a, which was based on a model describing water uptake in polymer above the glass transition. Using this approach, the implication of the glass transition in the mechanism of water uptake in seeds was demonstrated.

\subsection{Hypothesis of the mechanism describing water uptake in pulse seeds}

As the implication of the glass transition in the mechanism of water uptake provided in section 5.1 mainly depends upon the experimental data fitting models, a hypothesis for the mechanism of water uptake for seeds possessing seed coats with a glass transition above ambient soaking conditions has been developed based on an analogy between a temperature driven glass transition $\left(\mathrm{T}_{\mathrm{g}}\right)$ and a solvent driven glass transition $(\mathrm{ag})$ presented in polymer science literature (Laschitsch et al. 1999; Leibler \& Sekimota 1993; Vrentas \& Vrentas 1991). At a constant temperature, a sorption curve of a polymer below the glass transition remains relatively flat (i.e. possesses a lag period) until a certain solvent 
concentration is attained, after which the sorption curve displays a steep increase in solvent uptake. This steep increase in solvent uptake can be considered to have occurred the glass transition solvent activity $(\mathrm{ag})$ and consequently this increase in solvent uptake can be attributed to the plasticization of the polymer by the sorbed penetrant ( $\mathrm{Li} \&$ Lee, 2006; Vrentas \& Vrentas 1991). For polymers in the glassy state (i.e. below the glass transition), the length of time required to reach a saturated surface concentration, a state where water uptake is exponential, is affected by solvent content of the polymer and temperature (Fujita, 1961). If the seed coat of legume seeds has a glass transition below soaking temperature, it can be considered a biopolymer in the glassy state, thus the length of time required to reach saturated surface concentration would be affected by the temperature of the soaking water. Higher soaking temperatures would allow for more molecular movement and therefore promote faster attainment of saturated surface conditions, consequently reducing the lag time. This result was observed with the green bean data of Lui et al. (2005).

Furthermore, the thermal behavior of the seed coat of the unprocessed AC Ole bean seed was examined with differential scanning calorimetry (Ross et al., 2010b) to further test this hypothesis. The seed coat was placed in distilled water under isothermal conditions at $25^{\circ} \mathrm{C}$ with the aim of imitating soaking conditions. The heat flow was measured as a function of time and subsequently the rate of heat flow change was examined as a function of soaking time. The DSC data showed a sharp change in the amount of energy needed for soaking per unit time up to the two hour time point. Around the two hour time point, the change in the energy rate slows down and by four hours of soaking the energy rate seems to plateau. This result indicated an energy barrier to soaking exists in the first two hours of soaking, which does agree with the lag time observed in the water uptake data for the unprocessed AC Ole bean seed (Table 3). The gradual energy rate change from two hours to four hours corresponds to the concave up portion of the water uptake curve and the four hour time point after which the energy rate change becomes constant corresponds with the inflection point of the water uptake curve and may correspond to the time required to reach surface concentration saturation. The rate of energy change in the seed coats upon soaking is affected by the amount of water sorbed by the seed coat at a constant temperature. The time point where there is a substantial variation in the rate of energy change corresponds to the seed coat adsorbing the necessary amount of water (i.e. solvent) required to cause the seed coat to have a glass transition at room temperature. This time point corresponds to the lag time. After the seed coat moves through the glass transition temperature, the energy barrier to water uptake is lessened. These results are in agreement with the work of Gunnells et al. (1994) where it was shown that the glass transition temperature of wood when measured with DSC corresponded to the temperature where there was a maximum in the first derivative of heat flow (i.e. rate of energy change) after a steep increase.

The hypothesis for the mechanism of water uptake in seeds possessing seed coats with a glass transition near ambient soaking conditions was based on work reported in the field of polymer science. Polymers at their glass transition have a small relaxation time which allows for a sudden, almost instantaneous, increase to a saturated surface concentration 
upon exposure to solvent (Fujita, 1961; Richman \& Long, 1960) and therefore rapid initial solvent uptake is achieved. Thus, seeds that possess seed coats with a glass transition temperature near ambient temperature reach a saturated surface concentration rapidly upon immersion in water and exhibit exponential water uptake behavior with no significant lag time. Consequently, water uptake in seeds that possess seed coats with a glass transition temperature near ambient temperature and were successfully modelled with the exponential equation provided by Kanamaru \& Hirata (1969) used for describing solvent uptake by polymers above the glass transition.

\section{A polymer science approach to dehulling of pulses: The role of the glass transition}

\subsection{Importance of optimizing red lentil dehulling efficiency}

This section provides original experimental evidence determined by the authors which supports the role of the glass transition in defining the dehulling quality of red lentils and is presented as such. Red lentils account for the majority of world lentil production and trade (Agblor, 2006). With the exception of North America and Australia, most lentils are consumed in the region of production. Thus, the export market for red lentils is of paramount importance to North American and Australian producers. More than $90 \%$ of red lentils produced are consumed as dehulled split or dehulled whole seeds (Vandenberg \& Bruce, 2008). Since most red lentils are dehulled before consumption, milling or dehulling efficiency of red lentil is very important to consumer acceptability. For this work, dehulling efficiency (DE) as indicated by Wood \& Malcolmson (2011), was defined as the sum of dehulled whole seed (DW) and dehulled split seed (DS) relative to total initial mass of seeds. Dehulling efficiency is an important quality characteristic for lentil breeders, processors, and exporters as it ultimately dictates whether a dehulling operation is economically feasible (Wang, 2005). Upon milling/dehulling, the various fractions are obtained: 1) powder, 2) breaks/broken cotyledons, 3) hull, undehulled whole seeds, 4) dehulled split seeds, and 5) dehulled whole seeds (Wang, 2005). The goal of milling is to completely dehull the red lentils while minimizing the production of powder, breaks and splits. Based on the above definition theoretical DE is about $92 \%$ (complete hull removal, no undehulled whole seeds, no breaks, and no powder), yet millers strive to achieve $85 \%$ DE as a DE $>80 \%$ is necessary to achieve an economically viable process (Vandenberg \& Bruce, 2008; Wang, 2005). Also a higher ratio of whole dehulled seeds to split seeds is desired as whole dehulled seeds are the most valuble fraction (Vandenberg \& Bruce, 2008).

The problem that Canadian red lentil producers face is that the Western Canadian climate is very different from global competitors. Canadian grown red lentils have a higher moisture content compared to non-Canadian grown red lentils, and as a result dehulling is difficult (Vandenberg \& Bruce, 2008). Red lentils are typically harvested at $16-18 \%$ moisture content and to ensure safe storage red lentils are dried to $13 \%$ moisture content or less (CGC, 2008; McVicar, 2006). The use of aeration fans to reduce moisture has been recommended (McVicar (2006) yet supplemental heat drying may be necessary and it has also been 
recommended that air temperatures should not exceed $45{ }^{\circ} \mathrm{C}$ (Saskatchewan Government, 2007). The Canadian grain grading system (CGC, 2008) indicates that broken seeds must be less than $2 \%$ and 3.5\% in Canada No. 1 and Canada No. 2 grades, respectively. The effect of drying temperature on the handling quality of whole seeds in terms of seed breakage upon handling has been investigated (Tang et al., 1990), however little work has been done on the effect of drying temperature on the milling quality of red lentils. Alternatively, a large amount of work has been performed in the area of understanding the effect of drying temperature on rice milling quality (Cao et al., 2004; Cnossen \& Siebenmorgen, 2000; Cnossen et al., 2003; Iguaz et al., 2006). The rice industry cites breakage of rice kernels during milling as one of its main problems (Iguaz et al., 2006). Rice must be dried to $12-13 \%$ moisture content for safe storage. During drying moisture content gradients are created within the rice kernels that induce stresses that can cause the rice kernels to fissure/crack (Cao et al., 2004). Fissured/cracked rice kernels usually break during milling which results in poor cooking quality and a low value product (Cao et al., 2004). The ultimate goal of the rice industry is to maximize head rice yield (HRY), which is defined as the weight in percentage of rough rice that remains as head rice (rice kernels are at least $3 / 4$ of the original kernel length) after milling (Cnossen \& Siebenmorgen, 2000). As analogous situation exists in red lentil dehulling where upon milling maximizing the whole dehulled seed fraction and minimizing broken cotyledons and split seeds is desired.

The concept of the glass transition $\left(\mathrm{T}_{\mathrm{g}}\right)$ has been used to explain rice kernel fissure/crack formation during drying and subsequent breakage during milling (Siebenmorgen et al., 2004). At temperatures below $T_{g}$, grain seeds exist in a glassy solid state, starch granules are compact, water is relatively immobile and diffusion of moisture inside a grain seed is slow while at temperatures above $\mathrm{T}_{\mathrm{g}}$, starch exists in a rubbery state, free volume is increased, the water associated with starch has greater mobility, and the diffusion of moisture is enhanced (Siebenmorgen et al., 2004). During rice drying, the temperature will increase and moisture will diffuse from the grain seed and a temperature and moisture content gradient will develop from the surface to the center of the grain seed (Cnosssen et al., 2003). The temperature gradient disappears rapidly but the moisture content gradient remains to play an important role during and after drying. During the equilibrating (sometimes termed tempering) stage, following drying, moisture migrates from the center (higher moisture region) to the surface of the grain seed (lower moisture region) and consequently the moisture content gradient decreases. If the equlibrating air temperature is below the $T_{g}$ of the grain seed, the seed will cool and go through a glass transition and become glassy as the grain seed temperature decreases. If a sufficient moisture content gradient exists when the tempering/equilibrating environment is one that produces a change of state of the starch (transitioning from the rubbery to the glassy state), the different sections of the grain seed (surface, midpoint, centre), resulting from the moisture content gradient, pass through the $\mathrm{T}_{\mathrm{g}}$ at different moisture content values, which is depicted by situation B of Figure 7 (Cnossen \& Siebenmorgen, 2000; Cnossen et al., 2003). Due to large differences in kernel properties between the rubbery and the glassy states, specifically the thermal expansion coefficients (Perdon et al., 2000; Cnossen et al., 2003), differential stresses within the grain seed will likely cause fissuring/cracking (Siebenmorgen et al., 2004). If the tempering/equilibrating air 
temperature is above $\mathrm{T}_{\mathrm{g}}$, then the moisture content will equilibrate between the different sections of the kernel (surface, midpoint, centre) and the moisture content gradient will cease to exist. Upon subsequent exposure to ambient temperature, the kernel will pass through the glass transition at a common moisture content, stresses will be minimized and therefore fissure/cracking will be minimized. This is illustrated in situation A of Figure 7. The hypothesis used to explain rice breakage was adopted to explain breakage and splitting in red lentils. The objectives of the research linking the glass transition with dehulling quality were to: 1 ) determine the glass transition temperature of two varieties of red lentils, Impact and Redberry as affected by moisture content; and 2) use knowledge of the glass transition temperature to examine the effect of drying temperature on dehulling efficiency in terms of breakage and the ratio of dehulled whole seeds to dehulled split seeds.

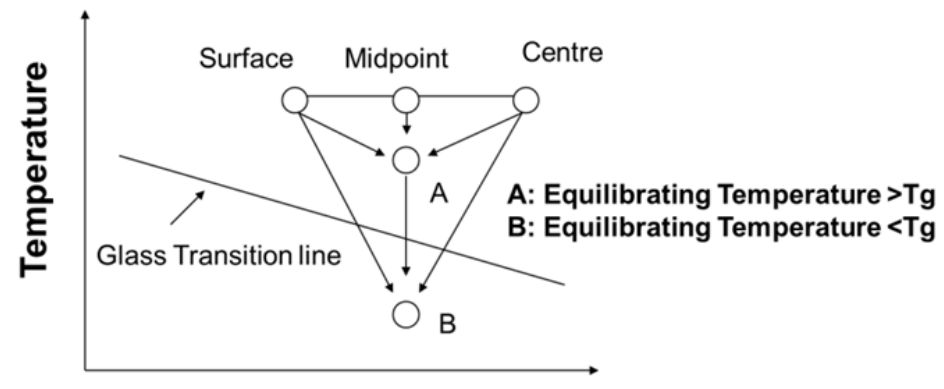

Moisture Content

Figure 7. Paths followed by the surface, mid-point between the surface and the center, and the center of the seed for an equilibration temperature above or below the glass transition $\left(\mathrm{Tg}_{\mathrm{g}}\right)$. (Adapted from Cnossen et al., 2003)

\subsection{Experimental work}

\subsubsection{Samples}

Two varieties of red lentils in commercial production (CDC Impact and CDC Redberry) were chosen for this study. Both lentil varieties (2007 crop) were grown in Saskatchewan and transported to the University of Manitoba in polyethylene bags in January 2008. The Impact and Redberry varieties were purchased as cleaned seeds and thus were relatively free of foreign materials upon arrival and did not require further cleaning prior to use.

\subsubsection{DSC Experiments}

\subsubsection{DSC Sample preparation}

Seed coats were removed from red lentil cotyledons by dehulling, which is described in detail in a following section. The red lentil cotyledon material was ground with a coffee grinder (Persona, ON) to reduce particle size and sieved to pass an $825 \mu \mathrm{m}$ sieve. Ground samples were sub-sampled and placed in four different relative humidity environments to 
alter the moisture content of the samples. The saturated salt solutions used were lithium chloride $(\mathrm{LiCl})$, potassium acetate, $(\mathrm{KAc})$, magnesium nitrate $\left(\mathrm{MgNO}_{3}\right)$, and sodium chloride $(\mathrm{NaCl})$ (Sigma Chemicals, St. Louis, MO) and they produced the following $\mathrm{RH}$ environments respectively, $11.3,22.5,52.9$, and $75.3 \%$ at $25^{\circ} \mathrm{C}$. The samples were allowed to sit in the various relative humidity environments until a constant mass was attained. The moisture content of the ground samples were determined by drying duplicate samples for $24 \mathrm{~h}$ in a drying oven (Precision Thelco Laboratory Oven, Thermo Fisher Scientific, Waltham, MA) set at $130^{\circ} \mathrm{C}$.

\subsubsection{DSC conditions}

The $\mathrm{Tg}$ of the ground red lentil cotyledons were measured with differential scanning calorimetry (DSC). A DSC, (DSC7, Perkin Elmer, Norwalk, CT) equipped with a thermal analyzer controller (TAC7/DX, Perkin Elmer, Norwalk, CT) and Pyris software v.8 (Perkin Elmer, Shelton, CT) were used to obtain the DSC thermograms. Samples were heated isothermally at $5{ }^{\circ} \mathrm{C}$ for 3 minutes prior to temperature ramping. A temperature ramp of 10 and $30{ }^{\circ} \mathrm{C} / \mathrm{min}$ and a temperature range of 5 to $170{ }^{\circ} \mathrm{C}$ were employed. The DSC was calibrated with indium (melting point $=156.6{ }^{\circ} \mathrm{C}$ and enthalpy $=28 \mathrm{~J} / \mathrm{g}$ ). At least $25 \mathrm{mg}$ of ground sample was accurately weighed into sample pans. The sample pans were sealed and an empty sample pan was used for the reference. The $T_{g}$ of each thermogram was determined by identifying the transition corresponding to a mid-point in slope change in the heat capacity of the sample. $\mathrm{T}_{\mathrm{g}}$ measurements were performed in duplicate.

\subsubsection{Drying experiments: Preparation of lentils dried at 40 and $80^{\circ} \mathrm{C}$}

For the drying experiments, the methods of Ross et al. (2010c) were followed. Briefly, Impact and Redberry variety red lentils were subjected to near ambient drying at $40{ }^{\circ} \mathrm{C}$ and high temperature drying at $80{ }^{\circ} \mathrm{C}$. Since the samples in their native/untreated state had a moisture content of 7.4\% (Impact) and 9.2\% (Redberry), the samples were tempered prior to drying to create an initial moisture content $(\mathrm{mc})$ of $13 \%(\mathrm{wb})$. The tempered samples were left for at least $48 \mathrm{~h}$ at room temperature to absorb and evenly distribute moisture throughout the individual seeds. These samples were then rewetted to raise the mc to $18 \%$ $(\mathrm{wb})$ to simulate moisture content at harvest. A starting common moisture content of $13 \%$ was chosen to ensure a moisture content increase of $5 \%$ was imposed on all samples. Five hundred grams of lentils were placed in aluminium pans $(29.8 \times 21.6 \times 3.2 \mathrm{~cm})$ creating a 15 $\mathrm{mm}$ thin layer. The $80{ }^{\circ} \mathrm{C}$ dried samples were placed in a drying oven (Precision Thelco Laboratory Oven, Thermo Fisher Scientific, Waltham, MA) set at $80^{\circ} \mathrm{C}$ for $2 \mathrm{~h}$ to lower the moisture content of the samples to $11 \%$. The $40{ }^{\circ} \mathrm{C}$ dried samples were placed in an environmental chamber (model IH 400, Yamato, Tokyo, Japan) set at $40{ }^{\circ} \mathrm{C}$ for $6.75 \mathrm{~h}$ to lower the moisture content of the samples to $11 \%$. After drying, the samples were subsampled. A portion of both the 40 and $80{ }^{\circ} \mathrm{C}$ dried samples were placed in sealable polyethylene plastic bags. The bags were sealed and allowed to equilibrate at $25^{\circ} \mathrm{C}$ for $16 \mathrm{~h}$. A portion of both the 40 and $80^{\circ} \mathrm{C}$ dried samples were placed in air-tight glass jars and placed in a drying oven set a $72{ }^{\circ} \mathrm{C}$ for $1.5 \mathrm{~h}$. After heating at $72{ }^{\circ} \mathrm{C}$ for $1.5 \mathrm{~h}$, the samples 
were placed sealable polyethylene plastic bags. The bags were sealed and allowed to equilibrate at $25^{\circ} \mathrm{C}$ for $16 \mathrm{~h}$. After equilibrating at $25^{\circ} \mathrm{C}$ for $16 \mathrm{~h}$ the samples were prepared for dehulling.

\subsubsection{Dehulling conditions}

In order to prevent seed size from being a variable in the dehulling tests all seeds were passed through a series of sieves (Carter Day International Inc., Minneapolis, MN) with round hole openings of 5.56,4.76, 4.37, 3.97, and $3.37 \mathrm{~mm}$ diameter and separated into fractions to obtain red lentils with uniform size. For the Redberry seeds that had not been treated (i.e. native seed samples), the most abundant fraction $(90 \%)$ belonged to the size range of 4.37 to $5.56 \mathrm{~mm}$. The Impact seeds were smaller and showed more size heterogeneity; the most abundant fraction (78\%) for the native/untreated samples belonged in the size range of 3.97 to $4.76 \mathrm{~mm}$. Seeds fitting in these ranges after pre-milling treatment were used in the dehulling evaluation tests. This practice was in accordance with the work of Erksine et al. (1991) and Ross et al. (2010c).

A grain testing mill (TM05C, Satake Engineering Co., Hiroshima, Japan), fitted with a 36 mesh abrasive wheel was used for the dehulling tests. The dehulling experiments were performed using the methods of Ross et al. (2010c) and dehulling variables such as abrasive milling speed, milling time and milling moisture content were chosen in accordance with the work of Ross et al. (2010c) and Wang (2005) to achieve optimal dehulling efficiency (DE). The Impact and Redberry red lentil samples were milled in $30 \mathrm{~g}$ batches using an abrasive milling speed of $1100 \mathrm{RPM}$ for $40 \mathrm{~s}$. The samples were tempered to $12.9 \%$ moisture content prior to milling/dehulling. It should be noted that the moisture level at milling/dehulling was independent of the moisture content that the samples were tempered to simulate moisture content at harvest. Tempering samples prior to dehulling was considered a milling/dehulling pre-treatment. The Impact and Redberry red lentils were moisturized to $12.9 \%$ moisture content by adding the amount of water needed to achieve the desired sample moisture content. Tap water was added to the sample using a graduated cylinder, and then the plastic bag was sealed and shaken for at least $60 \mathrm{~s}$, ensuring that the lentils were evenly coated with water. For up to two hours after the initial addition of moisture, the bags were periodically shaken for $60 \mathrm{~s}$ at $30 \mathrm{~min}$ intervals. The sealed samples were left for $48 \mathrm{~h}$ at room temperature to absorb and evenly distribute moisture throughout the individual seeds. Upon completion of the $48 \mathrm{~h}$ tempering period the samples were milled/dehulled. After dehulling, the milled lentils were screened on a US standard No. 20 mesh sieve $(850 \mu \mathrm{m})$ to collect the powder. The milled seeds remaining on top of the $850 \mu \mathrm{m}$ sieves were separated into whole seeds, split seeds, broken seeds and hulls using the following method. The seeds were sent through a husk aspiration unit (S.K. Engineering and Allied Works, Bahraich, India) to remove the hulls. The seeds were then separated into split and whole fractions by sieving over a No. $4.5(1.79 \times 12.7 \mathrm{~mm})$ slotted sieve (Carter Day International Inc., Minneapolis, MN). The split seeds were screened on a US standard No. 8 sieve $(2.36 \mathrm{~mm})$ to separate out the broken seeds. The whole seeds were separated by hand into their respective hulled and dehulled classes. It is noted that the split seeds were visually 
inspected for contaminating attached hull, yet none to negligible amounts were detected. All fractions were weighed and then expressed as a proportion of the total original sample weight. Dehulling efficiency (DE) was defined as the sum of percent dehulled whole seed (DW) and percent dehulled split seed (DS) relative to total initial mass of seeds and was calculated as:

$$
D E(\%)=\left(\frac{M_{D W}+M_{D S}}{M_{T}}\right) * 100
$$

Where: MDw is mass of dehulled whole seeds, MDs is the mass of dehulled split seeds, $\mathrm{M}_{\mathrm{T}}$ is the total initial mass of seeds.

\subsubsection{Statistical analysis}

Statistical analysis was conducted using SAS Institute Inc. Software, version 9.1 (SAS Institute, 2001). Data were subjected to analysis of variance (ANOVA) with replication using the SAS PROC GLM procedure to generate Least square (LS) means. Significance was accepted at $\mathrm{p} \leq 0.05$.

\subsection{The role of the glass transition in defining the dehulling quality of red lentils}

\subsubsection{Determination of glass transition temperature $(\mathrm{Tg})$ of red lentils}

Table 4 shows the results for the $\mathrm{T}_{\mathrm{g}}$ of the ground red lentils samples as a function of moisture content. The data presented in Table 4 are the midpoint $T_{g}$ values. These results indicate a clear dependence of $\mathrm{Tg}_{\mathrm{g}}$ and moisture content, as sample moisture content increased, the $T_{g}$ decreased. This is in agreement with the work of Cao et al. (2004) and Perdon et al. 2000, which indicated that the second order transition associated with the glass transition temperature was correlated with moisture content. It should be noted that there was no significant difference between the moisture content of the samples stored in the relative humidity environment of the $\mathrm{LiCl}$ saturated salt solution and the relative humidity environment of the KAc salt solution. This result was unexpected as these saturated salt solutions provide different relative humidity environments 11.3 and $22.5 \%$ at $25{ }^{\circ} \mathrm{C}$, respectively. Although sufficient amounts of these salts were added to water to create a saturated solution, it could be that one of the containers failed to properly seal. Nevertheless, samples with at least three different moisture contents were tested and a clear relationship between $\mathrm{T}_{\mathrm{g}}$ and moisture content was observed. Table 4 also shows the effect of heating rate on measured $\mathrm{T}_{\mathrm{g}}$. Generally, as the heating rate is increased there was an observed increase in $\mathrm{T}_{\mathrm{g}}$, which in agreement with the work of Bruning \& Samer (1992).

Table 5 gives coefficients for the linear regression equation relating glass transition temperature $\left(\mathrm{T}_{\mathrm{g}}\right)$ with respect to moisture content of Redberry and Impact red lentils at two different heating rates. Using respective correlation coefficients in the equation relating 
moisture content and $\mathrm{T}_{\mathrm{g}}$, it was determined that Redberry red lentils with a moisture content of $11 \%$ would possess a $\mathrm{T}_{\mathrm{g}}$ of 66 and $69^{\circ} \mathrm{C}$ with a 10 and $30^{\circ} \mathrm{C} / \mathrm{min}$ heating rate, respectively while Impact red lentils with a moisture content of $11 \%$ would have a $\mathrm{T}_{\mathrm{g}}$ of 65 and $67{ }^{\circ} \mathrm{C}$ with a 10 and $30^{\circ} \mathrm{C} / \mathrm{min}$ heating rate, respectively. This equation is given as:

$$
\mathrm{Tg}=\beta_{1} \times M C+\beta_{0}
$$

Where: $\mathrm{T}_{\mathrm{g}}$ is the glass transition temperature $\left({ }^{\circ} \mathrm{C}\right) ; \mathrm{MC}$ is \% moisture content; $\beta_{1}$ is the slope of the regression line; $\beta_{0}$ is the $y$-intercept of the regression line.

\begin{tabular}{|c|c|c|c|c|c|}
\hline \multirow[t]{2}{*}{$\begin{array}{c}\text { Relative } \\
\text { Humidity } \\
\text { Environment }\end{array}$} & \multirow[t]{2}{*}{$\begin{array}{c}\text { Moisture } \\
\text { Content } \\
(\%)\end{array}$} & \multicolumn{2}{|c|}{$\begin{array}{c}\text { Heat Rate } \\
\left(10^{\circ} \mathrm{C} / \mathrm{min}\right) \\
\mathrm{T}_{\mathrm{g}}\left({ }^{\circ} \mathrm{C}\right)\end{array}$} & \multicolumn{2}{|c|}{$\begin{array}{c}\text { Heat Rate } \\
\left(30^{\circ} \mathrm{C} / \mathrm{min}\right) \\
\mathrm{T}_{\mathrm{g}}\left({ }^{\circ} \mathrm{C}\right)\end{array}$} \\
\hline & & Redberry & Impact & Redberry & Impact \\
\hline LiCl & $6.1 \mathrm{a}$ & $75.1 \mathrm{a}$ & $74.8 \mathrm{a}$ & $81.3 a$ & $79.1 \mathrm{a}$ \\
\hline KAC & $6.5 a$ & $71.7 \mathrm{a}$ & $76.0 \mathrm{a}$ & $78.9 a$ & $79.9 \mathrm{a}$ \\
\hline MgNO3 & $10.1 \mathrm{~b}$ & $66.7 \mathrm{~b}$ & $66.7 \mathrm{~b}$ & $74.5 \mathrm{~b}$ & $66.2 b$ \\
\hline $\mathrm{NaCl}$ & $14.0 \mathrm{c}$ & $62.2 c$ & $58.4 \mathrm{c}$ & $61.3 c$ & $60.5 c$ \\
\hline
\end{tabular}

Different letters within a column indicate significant differences between the means $(n=2)$

Table 4. Effect of Moisture Content and Heating Rate on $\mathrm{T}_{\mathrm{g}}$

\begin{tabular}{|c|c|c|c|c|c|c|}
\hline Variety & \multicolumn{3}{|c|}{$\begin{array}{c}\text { Heat Rate } \\
\left(\mathbf{1 0}{ }^{\circ} \mathrm{C} / \text { min) }\right.\end{array}$} & \multicolumn{3}{c|}{$\begin{array}{c}\text { Heat Rate } \\
\left(30^{\circ} \mathbf{C} / \text { min }\right)\end{array}$} \\
\hline & $\begin{array}{c}\mathrm{B}_{0} \\
\left({ }^{\circ} \mathrm{C}\right)\end{array}$ & $\mathrm{B}_{1}$ & $\mathrm{R}^{2}$ & $\begin{array}{c}\mathrm{B}_{0} \\
\left({ }^{\circ} \mathrm{C}\right)\end{array}$ & $\mathrm{B}_{1}$ & $\mathrm{R}^{2}$ \\
\hline Impact & 89.24 & -2.21 & 0.988 & 94.8 & -2.54 & 0.954 \\
\hline Redberry & 82.68 & -1.49 & 0.949 & 95.8 & -2.38 & 0.956 \\
\hline
\end{tabular}

$\mathrm{MC}$ is \% moisture content; $\beta_{1}$ is the slope of the regression line; $\beta_{0}$ is the $y$-intercept of the regression line; $R^{2}$ is correlation coefficient

Table 5. The Linear Relationship Between Glass Transition Temperature and Moisture Content for Red Lentils

The $\mathrm{T}_{\mathrm{g}}$ values obtained for the ground red lentil cotyledons were higher than the $\mathrm{T}_{\mathrm{g}}$ values obtained by Perdon et al. (2000) and Cao et al. (2004) for rice at comparable moisture contents. Possible reasons for this result may be due to the fact that ground red lentils were used instead of individual grain sections. It is possible that ground samples have different heat transfer properties than individual grain sections. Also, a cereal starch (rice) is different in composition than a legume starch (lentil). These different starches possess different granule organization and different degrees of branching which will affect $\mathrm{T}_{\mathrm{g}}$ (Parker \& Ring, 2001). Therefore it is not unreasonable to accept different $T_{g}$ values at a common moisture content for the different starch types. In all, for red lentils, the linear regression equations provided in Table 5 can be used to predict $\mathrm{T}_{\mathrm{g}}$ from moisture content. 


\subsubsection{Effect of drying $\mathcal{E}$ equilibration temperature on dehulling quality}

Table 6 shows the effect of drying temperature and equilibration temperature on the dehulling quality of Impact and Redberry red lentils. For the Impact red lentils, drying at a temperature above $\mathrm{Tg}_{\mathrm{g}}\left(80^{\circ} \mathrm{C}\right)$ and equilibrating at a temperature below $\mathrm{Tg}\left(25^{\circ} \mathrm{C}\right)$ did result in significantly more breaks, more split cotyledons and a significantly higher ratio of split seed to whole dehulled seeds than any other condition. Although drying below $\mathrm{T}_{\mathrm{g}}\left(40^{\circ} \mathrm{C}\right)$ and equilibrating below $\mathrm{Tg}\left(25^{\circ} \mathrm{C}\right)$ did result in significantly less breaks and split cotyledons than drying above $\mathrm{Tg}_{\mathrm{g}}\left(80^{\circ} \mathrm{C}\right)$ and tempering below $\mathrm{T}_{\mathrm{g}}\left(25^{\circ} \mathrm{C}\right)$, there were still significantly more breaks and split cotyledons observed compared to the reference (non-dried) Impact seeds. The Impact samples dried at either 40 or $80^{\circ} \mathrm{C}$ and equilibrated above $\mathrm{Tg}_{\mathrm{g}}\left(72{ }^{\circ} \mathrm{C}\right)$ resulted in a significant reduction in broken and split cotyledons. Within the Impact seeds equilibrated above $\mathrm{T}_{\mathrm{g}}$, the samples that were dried at $40{ }^{\circ} \mathrm{C}$ possessed significantly less splits compared to the Impact seed samples dried at $80{ }^{\circ} \mathrm{C}$ upon milling. Also, the ratio of split to dehulled whole seeds and dehulling efficiency (DE) of the Impact samples, dried at either 40 or $80{ }^{\circ} \mathrm{C}$ and equilibrated above $\mathrm{T}_{\mathrm{g}}\left(72^{\circ} \mathrm{C}\right)$ was not significantly different than the Impact samples that were not subjected to any artificial drying. For the Redberry red lentils, drying at either 40 or $80^{\circ} \mathrm{C}$ and equilibrating at a temperature below $\mathrm{Tg}_{\mathrm{g}}\left(25^{\circ} \mathrm{C}\right)$ did result in significantly more split cotyledons and a significantly higher ratio of split seed to whole dehulled seeds than the condition of drying below or above $\mathrm{Tg}_{\mathrm{g}}\left(40\right.$ or $80^{\circ} \mathrm{C}$ ) and equilibrating above $\mathrm{Tg}_{\mathrm{g}}\left(72{ }^{\circ} \mathrm{C}\right)$. Within the Redberry seed samples equilibrated above $\mathrm{T}_{\mathrm{g}}\left(72{ }^{\circ} \mathrm{C}\right)$ or below $\mathrm{T}_{\mathrm{g}}\left(40^{\circ} \mathrm{C}\right)$, the Redberry samples that were dried at $40{ }^{\circ} \mathrm{C}$ possessed significantly less splits compared to the sampled dried at $80{ }^{\circ} \mathrm{C}$ upon milling. For the Redberry seeds, there was no observed effect on the amount of breaks or dehulling efficiency (DE) at any drying and equilibrating condition. Therefore the results observed for Redberry showed that equilibrating above $\mathrm{T}_{\mathrm{g}}\left(72{ }^{\circ} \mathrm{C}\right)$ resulted in a significant reduction in split cotyledons. Additionally, the ratio of split to dehulled whole seeds for the Redberry samples that were equilibrated above $T_{g}\left(72{ }^{\circ} \mathrm{C}\right)$ was not significantly different than the Redberry samples that were not subjected to any artificial drying (i.e. the reference samples).

For both red lentil varieties, in the situation where the samples were dried below $\mathrm{T}_{\mathrm{g}}\left(40{ }^{\circ} \mathrm{C}\right)$ and equilibrated at a temperature below $\mathrm{T}_{\mathrm{g}}\left(25^{\circ} \mathrm{C}\right)$, there should be no change of phase of starch and therefore no or limited stress gradient should result as will result as the surface, midpoint and center of the grain reach a common moisture content. Breakage and splitting upon dehulling should be minimized. Although the results of this work seemed to indicate drying below and equilibrating below $\mathrm{T}_{\mathrm{g}}$ will negatively impact dehulling quality as significantly higher values of split seeds were obtained for this condition compared to values observed for samples equilibrated above $\mathrm{Tg}$. Possibly the drying temperature used in these experiments were too close to the measured $\mathrm{T}_{\mathrm{g}}$ values and possibly overlapped onset $\mathrm{T}_{\mathrm{g}}$ values. However, seeds dried at the higher temperature condition $\left(80^{\circ} \mathrm{C}\right)$ and equilibrated below $\mathrm{Tg}\left(25^{\circ} \mathrm{C}\right)$ showed even higher levels of split seeds than those dried at the lower temperature condition $\left(40^{\circ} \mathrm{C}\right)$ and equilibrated below $\mathrm{Tg}_{\mathrm{g}}\left(25^{\circ} \mathrm{C}\right)$, which helps to support this explanation. Also, research in rice drying has shown that the use of higher drying temperature promote rice fissuring and breakage upon milling. When higher drying temperatures are employed, the rate of moisture removal increases which promotes the development stress 
gradients within the seed and thereby promotes fissuring and breakage (Iguaz et al., 2006). When the samples are dried below $\mathrm{T}_{\mathrm{g}}$ and equilibrated at a temperature above $\mathrm{T}_{\mathrm{g}}$, the starch will experience a change of state, yet the surface, midpoint, and center of the seed will reach a common moisture content above $\mathrm{T}_{\mathrm{g}}$ and stress gradients will also be minimized. This situation would also lead to less breakage and splitting upon dehulling, which as observed in this work. When the samples are dried above $T_{g}$ and equilibrated at a temperature above $T_{g}$, the starch will be in the rubbery state and the seed will reach a common moisture content above $\mathrm{T}_{\mathrm{g}}$ and stress gradients will also be minimized. This situation would also lead to less breakage and splitting upon dehulling, which was observed in this work. However, samples dried above $\mathrm{T}_{\mathrm{g}}$ $\left(80^{\circ} \mathrm{C}\right)$ and equilibrated above $\mathrm{T}_{\mathrm{g}}\left(72^{\circ} \mathrm{C}\right)$ presented more splits than corresponding samples dried below $\mathrm{T}_{\mathrm{g}}\left(25^{\circ} \mathrm{C}\right)$ and equilibrated above $\mathrm{T}_{\mathrm{g}}\left(72^{\circ} \mathrm{C}\right)$.

\begin{tabular}{|l|c|c|c|c|c|c|c|c|c|c|c|}
\hline Samples & $\begin{array}{c}\text { Drying } \\
\text { Temp } \\
\left({ }^{\circ} \mathbf{C}\right)\end{array}$ & $\begin{array}{c}\text { Equilib } \\
\text { Temp } \\
\left({ }^{\circ} \mathbf{C}\right)\end{array}$ & $\begin{array}{c}\text { MC } \\
\mathbf{( \% )}\end{array}$ & $\begin{array}{c}\text { Powder } \\
\mathbf{( \% )}\end{array}$ & $\begin{array}{c}\text { Breaks } \\
\mathbf{( \% )}\end{array}$ & $\begin{array}{c}\text { Hull } \\
\mathbf{( \% )}\end{array}$ & $\begin{array}{c}\text { UDW } \\
\mathbf{( \% )}\end{array}$ & $\begin{array}{c}\text { DW } \\
\mathbf{( \% )}\end{array}$ & $\begin{array}{c}\text { DS } \\
\mathbf{( \% )}\end{array}$ & $\begin{array}{c}\text { DE } \\
\mathbf{( \% )}\end{array}$ & $\begin{array}{c}\text { DS:DW } \\
\text { Ratio }\end{array}$ \\
\hline Impact & 40 & 25 & 11.1 & $1.58 \mathrm{a}$ & $0.73 \mathrm{a}$ & $8.0 \mathrm{~s}$ & $12.1 \mathrm{a}$ & $22.2 \mathrm{a}$ & $55.1 \mathrm{a}$ & $77.1 \mathrm{a}$ & $2.5 \mathrm{a}$ \\
\hline Impact & 80 & 25 & 11.2 & $1.47 \mathrm{a}$ & $1.26 \mathrm{~b}$ & $7.6 \mathrm{a}$ & $10.0 \mathrm{a}$ & $15.5 \mathrm{~b}$ & $61.2 \mathrm{~b}$ & $76.7 \mathrm{a}$ & $3.9 \mathrm{~b}$ \\
\hline Impact & 40 & 72 & 11.2 & $1.75 \mathrm{a}$ & $0.75 \mathrm{a}$ & $7.3 \mathrm{a}$ & $3.4 \mathrm{~b}$ & $63.1 \mathrm{c}$ & $23.5 \mathrm{c}$ & $86.6 \mathrm{~b}$ & $0.37 \mathrm{c}$ \\
\hline Impact & 80 & 72 & 11.2 & $1.60 \mathrm{a}$ & $0.90 \mathrm{a}$ & $7.2 \mathrm{a}$ & $4.6 \mathrm{~b}$ & $53.0 \mathrm{~d}$ & $32.5 \mathrm{~d}$ & $85.5 \mathrm{~b}$ & $0.62 \mathrm{c}$ \\
\hline Impact: \\
Reference & $\mathrm{Na}$ & $\mathrm{na}$ & $\begin{array}{c}7.4 \\
\text { “as is" }\end{array}$ & $1.94 \mathrm{a}$ & $0 \mathrm{c}$ & $7.4 \mathrm{a}$ & $2.7 \mathrm{~b}$ & $63.4 \mathrm{c}$ & $23.5 \mathrm{c}$ & $86.9 \mathrm{~b}$ & $0.37 \mathrm{c}$ \\
\hline Redberry & 40 & 25 & 11.3 & $1.89 \mathrm{a}$ & $0.23 \mathrm{a}$ & $8.6 \mathrm{a}$ & $3.4 \mathrm{a}$ & $50.1 \mathrm{a}$ & $35.0 \mathrm{a}$ & $85.2 \mathrm{a}$ & $0.7 \mathrm{a}$ \\
\hline Redberry & 80 & 25 & 11.2 & $1.92 \mathrm{a}$ & $0.18 \mathrm{a}$ & $8.6 \mathrm{a}$ & $2.95 \mathrm{a}$ & $42.1 \mathrm{~b}$ & $42.8 \mathrm{~b}$ & $84.9 \mathrm{a}$ & $1.1 \mathrm{~b}$ \\
\hline Redberry & 40 & 72 & 11.2 & $1.62 \mathrm{a}$ & $0.27 \mathrm{a}$ & $9.2 \mathrm{~b}$ & $1.15 \mathrm{a}$ & $77.7 \mathrm{c}$ & $10.8 \mathrm{c}$ & $88.5 \mathrm{a}$ & $0.14 \mathrm{~cd}$ \\
\hline Redberry & 80 & 72 & 11.1 & $1.90 \mathrm{a}$ & $0.22 \mathrm{a}$ & $8.3 \mathrm{a}$ & $0.73 \mathrm{a}$ & $71.1 \mathrm{~d}$ & $17.3 \mathrm{~d}$ & $88.4 \mathrm{a}$ & $0.24 \mathrm{c}$ \\
\hline Redberry: \\
Reference & $\mathrm{Na}$ & $\mathrm{na}$ & 9.2 & $2.06 \mathrm{a}$ & $0 \mathrm{~b}$ & $8.2 \mathrm{a}$ & $0 \mathrm{~b}$ & $59.1 \mathrm{e}$ & $28.5 \mathrm{e}$ & $87.6 \mathrm{a}$ & $0.49 \mathrm{ac}$ \\
\hline
\end{tabular}

MC= moisture content; Powder=powder yielded from dehulling; Breaks=broken seed yielded from dehulling; Hull=hull yielded upon dehulling; UDW=Undehulled whole seeds yielded from dehulling; DW=Dehulled whole seeds yielded from dehulling; DS=dehulled split seeds yielded from dehuling; DE=Dehulling Efficiency; na=not applicable Different letters within a column and variety indicate significant differences between the means $(\mathrm{n}=2)$

Table 6. Effect of Drying Temperature and Equilibration Temperature on Dehulling Quality 
In summary of this experimental work, moisture content has a significant effect on the thermal properties of Redberry and Impact variety red lentils. The glass transition temperature, $\mathrm{Tg}$, increased with decreasing moisture content. Single broad transitions were observed from the DSC thermograms of Redberry and Impact variety red lentils at different moisture contents. The linear equations calculated to predict $\mathrm{T}_{\mathrm{g}}$ from moisture content proved useful in understanding the mechanism of red lentil breakage and splitting from drying and milling. With knowledge of the $\mathrm{T}_{\mathrm{g}}$, the experimental procedure tested the $\mathrm{T}_{\mathrm{g}}$ drying hypothesis by drying and equilibrating the red lentils at temperatures above and below their $\mathrm{T}_{\mathrm{g}}$. Results for both varieties of red lentils showed that equilibration of the dried lentils at temperatures above $\mathrm{T}_{\mathrm{g}}$ caused a decrease in splitting, implying that stress gradients were minimized using this treatment. Also, equilibrating dried samples at a temperature above $\mathrm{T}_{\mathrm{g}}$ caused a remarkable increase in the ratio of dehulled whole lentils to split lentils. The Impact variety red lentils also showed significantly less breaks and a higher dehulling efficiency when equilibrated above $\mathrm{T}_{\mathrm{g}}$ for either drying condition. Therefore, the results that were obtained in this work are supported by the rice drying hypothesis put forth by Cnossen \& Siebenmorgen (2000) and indicated that the splitting of cotyledons upon dehulling was more affected by drying temperature and equilibration temperature than breakage.

\section{Conclusion}

To the best of the authors' knowledge, no other work has explicitly linked the glass transition of the seed coat with water uptake behaviour. Implication of the glass transition of the seed coat as a key factor influencing water uptake is important as delayed water uptake behavior has served as the main impediment to the processing of legumes and the creation of value added whole seed legume products. A detailed chemical analysis of components in the seed coat affecting the glass transition temperature is required in future work as it would allow for focussed breeding efforts to reduce the chemical components that cause high seed coat glass transition temperatures thereby improving the processability of some legume seeds. The concept of the glass transition has been used to explain rice kernel fissure formation during drying and subsequent breakage during milling of rice. The hypothesis used to explain rice breakage was adopted to explain breakage and splitting in red lentils upon dehulling. Red lentil varieties, Impact and Redberry, showed an increase in the amount of split seeds when dried above or below $\mathrm{T}_{\mathrm{g}}$ and equilibrated below $\mathrm{T}_{\mathrm{g}}$. The red lentils that were dried above or below $\mathrm{T}_{\mathrm{g}}$ and equilibrated at temperatures above $\mathrm{T}_{\mathrm{g}}$ showed a significant decrease in splitting. The Impact variety also showed significant decrease in seed breakage and increased dehulling efficiency. Furthermore, equilibrating dried samples above $\mathrm{T}_{\mathrm{g}}$ caused a remarkable increase in the ratio of dehulled whole seeds to split seeds. Future work must include investigating: a minimum equilibration temperature, a minimum equilibration time, a maximum moisture content removal per drying step, a very gentle drying condition $\left(21^{\circ} \mathrm{C}\right.$ at $\left.50 \% \mathrm{RH}\right)$ and the effects on dehulling quality. However, the work at present does implicate the $\mathrm{T}_{\mathrm{g}}$ as having an effect on breakage and splitting of red lentils. Overall, the challenges in pulse processing can be addressed by a following a polymer science approach. 


\section{Author details}

Kelly A. Ross*

Agriculture \& Agri-Food, Canada

Susan D. Arntfield

Dept. of Food Science, University of Manitoba Canada

Stefan Cenkowski

Dept. Biosystems Engineering, University of Manitoba, Canada

\section{References}

Abbas, K.A.; Lasekan, O. \& Khalil, S.K. (2010). The Significance of Glass Transition Temperature in Processing of Selected Fried Food Products: A Review. Modern Applied Science, Vol.4, No.5, pp. 3-21.

Abu-Ghannam, N. \& Gowen, A. (2011). Pulse-based food products. In: Pulse Foods: Processing, Quality and Nutraceutical Applications, B. Tiwari, A. Gowen, B. McKenna (Eds.), 249-278, Academic Press

Abu-Ghannam, N. \& McKenna, B.; (1997). The Application of Peleg's Equation to Model Water Absorption During the Soaking of Red Kidney Beans (Phaseolus vulgaris L.). Journal of Food Engineering, Vol.32, pp. 391-401.

Agblor, K. (2006). The Cropportunity Strategy for Red Lentils-Spot Light on Research. PulsePoint. June, pp.25-27: Saskatchewan Pulse Growers.

An, D.; Arntfield, S.D.; Beta, T. \& Cenkowski, S.; (2010). Hydration Properties of Different Varieties of Canadian Field Peas (Pisum sativum) form Different Locations. Food Research International, Vol.43, No.2, pp. 520-525.

Arechavaleta-Medina, F. \& Snyder, H.E. (1981). Water Imbibition by Normal and Hard Soybeans. Journal of the American Oil Chemical Society, Vol.58, pp.976-979.

Argel, P.J. \& Parton, C.J. (1999). Overcoming Legume Hardseededness. In: Forage Seed Production: Tropical and Sub-tropical Species, D.S. Loch, J.E. Ferguson (Eds.), 247-267, CAB International, Wallingford.

Barbosa-Cánovas G.V. \& Vega-Mercado, H. (1996). Physical, Chemical, and Microbiological Characteristics of Dehydrated Foods. In: Dehydration of Foods, G.V. Barbosa-Canovas \& H. Vega-Mercado (Eds.), 29-99, International Thompson Publishing, New York, USA.

Bellido, G.; Arntfield, S.D.; Cenkowski, S. \& Scanlon, M.G. (2006). Effects of micronization pretreatments on the physicochemicalproperties of navy and black beans (Phaseolus vulgaris L.) Lebensm. Wiss. Technol. Vol.39, pp. 779-787.

Black, R.G.; Singh, U. \& Meares, C. (1998a). Effect of Genotype and Pre-Treatment of Field Peas (Pisum Sativum) on their Dehulling and Cooking Quality. Journal of the Science of Food and Agriculture, Vol.77, pp. 251-258.

Black, R.G.; Brouwer, J.B.; Meares, C. \& Iyer, L. (1998b). Variation in Physico-Chemical Properties of Field Peas (Pisum sativum). Food Research International, Vol.31, pp. 81-86.

* Corresponding Author 
Boye, J.; Zare, F. \& Pletch, A. (2010). Pulse Proteins: Processing, Characterization, Functional Properties and Applications in Food and Feed Food Research International, Vol.43, pp. 414-431.

Brent, J.L.; Mulvaney, S.J.; Cohen, C. \& Bartsch, J.A. (1997). Thermomechanical Glass Transition of Extruded Cereal Melts. Journal of Cereal Science, Vol. 26, pp. 301-312.

Bruning, R. \& Samer, K. (1992). Glass Transition on Long Time Scales. Physics Review B Vol.46, No.18, pp. 11318-11322.

Campanella, O.H.; Li, P.X.; Ross, K.A. \& Okos, M.R. (2002). The Role of Rheology in Extrusion. In: Engineering and Food for the 21st Century, J. Welti-Chanes, G.V. BarbosaCanovas, J.M. Aguilera (Eds.), 393-413, Technomic Publishing.

Canadian Grain Commission (2008). Official Grain Grading Guide - Lentils (Chapter 18) Canadian Grain Commission ISSN 1704-5118.

Cao, W.; Nishiyama, Y. \& Koide, S. (2004). Physicochemical, Mechanical, and Thermal Properties of Brown Rice with Various Moisture Contents. International Journal of Food Science and Technology, Vol.39 pp. 899-906.

Casado, C.G. \& Heredia, A. (2001). Specific Heat Determination of Plant Barrier Lipophillic Components: Biological Implications. Biochimica et Biophysica Acta Vol.1511, pp. 291-296.

Cnossen, A.G.; Jimenez, M.J. \& Siebenmorgen, T.J. (2003). Rice Fissuring Response to High Drying and High Tempering Temperatures. Journal of Food Engineering, Vol.59, pp. 6169.

Cnossen, A.G. \& Siebenmorgen. TJ. (2000). The Glass Transition Temperature Concept in Rice Drying and Tempering Effect on Milling Quality. Transactions of the ASAE, Vol. 23, pp. 1661-1667.

DeSouza, F.H., \& Marcos-Filho, J. (2001). The seed coat as a modulator in seed-environment relationships in Fabaceae. Revta Brasil Botany, Vol.24, No.4, pp. 365-375.

Debendedetti, P.G. \& Stillinger, F.H. (2001). Supercooled liquids and the glass transition. Nature, Vol49, pp.259-267.

Ferry, J.D. (1980). Viscoelastic Properties of Polymers. 3rd ed. John Wiley \& Sons, New York. $641 \mathrm{p}$.

Eckl, K. \& Gruler, H. (1980). Phase Transitions in Plant Cuticles. Planta, Vol. 1150, pp. 102113.

Egerton-Warburton, L.M. (1998). A Smoke Induced Alteration of the Sub-Testa Cuticle in Seed of the Post Fire Recruiter, Emmenanthe penduliflora Benth. (Hydrophyllaceae). Journal of Experimental Botany, Vol.49, No.325, pp. 1317-1327.

Flory, P.J. (1953). Principles of Polymer Chemistry. Cornell University Press, Ithaca, New York. 672 p.

Fujita, H. (1961). Diffusion in Polymer-Diluent Systems. Algebra Universalis, Vol.3, No.1, pp. $1-47$.

Gibbs, J.H. (1956). Nature of the Glass Transition in Polymers. Journal of Chemical Physics, Vol.25, pp. 185-186.

Gibbs, J.H. \& DiMarzio, E.A. (1958). Nature of the Glass Transition and the Glassy State. Journal of Chemical Physics, Vol.,28, pp. 373-383. 
Gunnells, D.W.; Gardner, D.J. \& Wolcott, M.P. (1994). Temperature Dependence of Wood Surface Energy. Wood and Fibre Science, Vol.26, No.4, pp. 447-455.

Hoseney, R.C. Glass Transition and its Role in Cereals. 1994. In: Principles of Cereal Science and Technology, R.C. Hoseney (Ed.), 307-320, American Association of Cereal Chemists, St. Paul, MN.

Hsu, K.H. (1983a). A Diffusion Model with a Concentration-Dependent Diffusion Coefficient for Describing Water Movement in Legumes During Soaking. Journal of Food Science, Vol.48, pp, 618-622,645.

Hsu, K.H. (1983b). Effect of Temperature on Water Diffusion in Soybean. Journal of Food Science, Vol.48, pp. 1364-1365.

Hung, T.V.; Liu, L.H.; Black, R.G. \& Trewhella, M.A. (1993). Water Absorption in Chickpea (C. arietinum) and Field Pea (Pisum sativum) Cultivars Using the Peleg Model. Journal of Food Science, Vol.58, pp. 848-852.

Iguaz, A.; Rodriguez, M. \& Virseda, P. (2006). Influence of handling and processing of rough rice on fissure and head rice yields. Journal of Food Engineering, Vol. 77, pp. 803-809.

Kanamaru, K,. \& Hirata, M. (1969). The Two-Stage Sorption Process of Polymers Immersed in Water Viewed from the Process of the Lowering of $\xi$-Potential with Time. Colloid Polymer Science, Vol.230, No.1, pp. 206-221.

King, R.D. \& Ashton, S.J. (1985). Effect of Seed Coat Thickness and Blanching on the Water Absorption by Soybeans. Journal of Food Technology, Vol.20, pp. 505-509.

Kon, S. (1979). Effect of Soaking Temperature on Cooking and Nutritional Quality of Beans. Journal of Food Science, Vol.44, pp. 1329-1334, 1340.

Kumagai, H. \& Kumaga, H. (2009). Glass Transition of Foods and Water's Effect on It. Foods Food Ingredients Journal of Japan, Vol.214, No.2. pp. 1.

Laschitsch, A.; Bouchard, C.; Habicht, J.; Schimmel, M.; Ruhe, J. \& Johannsmann, D. (1999). Thickness Dependence of the Solvent Induced Glass Transition in Polymer Brushes. Macromolecules, Vol.32, pp. 1244-1251.

Leibler, L. \& Sekimota, K. (1993). On the Sorption of Gases and Liquids in Glassy Polymers. Macromolecules, Vol.26, pp. 6937-6939.

Lemeste, M.; Champion, D.; Roudaut, G.; Blond, G. \& Simatos, D. (2002). Glass Transition and Food Technology: A Critical Appraisal. Journal of Food Science, Vol.67, No.7, pp. 2444-2458.

Li, J.X. \& Lee, P.I. (2006). Effect of Sample Size on Case II Diffusion of Methanol in Poly(Methyl Methacylate) Beads. Polymer, Vol.47, pp. 7726-7730.

Li, Q. (2010). Investigating the Glassy to Rubbery Transition of Polydextrose and Corn Flakes Using Automatic Water Vapor Sorption Instruments, DSC, and Texture Analysis [Thesis]. Urbana, IL: University of Illinois at Urbana-Champaign.

Lin, L.S. ; Yuen, H.K. \& Varner, J.E. (1991). Differential Scanning Calorimetry of Plant Cell Walls. Proceeding of the National Academy of Sciences, Vol.88, pp. 2241-2243.

Liu, C.K.; Lee, S.; Cheng, W.J.; Wu, C.J. \& Lee, I.F. (2005). Water absorption in dried beans. Journal of the Science of Food and Agriculture, Vol.85, pp. 1001-1008. 
Ma, F.; Cholewa, E.; Mohamed, T.; Peterson, C.A. \& Gijzen, M. (2004). Cracks in the Palisade Cuticle of Soybean Seed Coats Correlate with their Permeability to Water. Annals of Botany, Vol.94, pp. 213-228.

Marbach, I. \& Mayer, A.M. (1975). Changes in Catechol Oxidase and Permeability to Water in Seed Coats of Pisum elatius during Seed Development and Maturation. Plant Physiology, Vol.56, pp. 93-96.

Marbach I. \& Mayer, A.M. (1974). Permeability of Seed Coats to Water as Related to Drying Conditions and Metabolism of Phenolics. Plant Physiology, Vol.54, pp. 817-820.

Maskus, H. (2010). Pulse Processing, Functionality and Application-Literature Review. Pulse Canada. pp. 1-146.

Matas, A.J.; Cuartero, J. \& Heredia, A. (2004). Phase Transitions in the Biopolyester Cutin Isolated from Tomato Fruit Cuticles. Thermochimica Acta, Vol.409, pp. 165-168.

Matas, A.J.; Lopez-Casado, G.; Cuartero, J. \& Heredia, A. (2005). Relative Humidity and Temperature Modify the Mechanical Properties of Isolated Tomato Fruit Cuticles. American Journal of Botany, Vol.92, No.3, pp. 462-468.

McVicar, R. (2006). Red Lentils: Handle with Care. PulsePoint. June, p.9-10.

McDougall, G.J.; Morrison, I.M.; Stewart, D. \& Hillman, J.R. (1996). Plant Cell Walls as Dietary Fiber: Range, Structure, Processing and Function. Journal of the Science of Food and Agriculture, Vol.70, pp. 133-150.

Meyer, C.J.; Steudle, E. \& Peterson, C.A. (2007). Patterns and Kinetics of Water Uptake by Soybean Seeds. Journal of Experimental Botany, Vol.58, pp. 717-732.

Mullin, W.J. \& Xu, W. (2001). Study of Soybean Seed Coat Components and Their Relationship to Water Absorption. Journal of Agricultural and Food Chemistry, Vol.49, No.11, pp. 5331-5335.

Nakano, T. (1994a). Non-Steady State Water Adsorption of Wood. Part 1. A Formulation for Water Adsorption. Wood Science Technology, Vol. 28, pp. 359-363.

Nakano, T. (1994b). Non-Steady State Water Adsorption of Wood. Part 2. Validity of the Theoretical Equation of Water Adsorption. Wood Science Technology, Vol.28, pp. 450-456.

Norton, C. (1998). Texture and Hydration of Expanded Rice. [Thesis] Nottingham University.

Oksanen, C.A. \& Zografi, G. (1990). The Relationship Between the Glassy Transition Temperature and Water Vapor Absorption by Poly(Vinylpyrrolidone). Pharmaceutical Research, Vol.7, No.6, pp. 654-7.

Parker, R. \& Ring, S.G. (2001). Aspects of the Physical Chemistry of Starch. Journal of Cereal Science Vol.34, pp. 1-17.

Peleg, M. (1988). An Empirical Model for the Description of Moisture Sorption Curves. Journal of Food Science, Vol.53, pp. 1216-1217, 1219.

Peleg, M. (1993). Mapping The Stiffness-Temperature-Moisture Relationship of Solid Biomaterials at and Around Their Glass Transition. Rheologica Acta, Vol.32, No.6, pp. 575-580.

Peleg, M. (1994a). A Model of the Mechanical Changes in Biomaterials at and Around their Glass Transition. Biotechnology Progress, Vol.10, pp. 385-388. 
Peleg, M. (1994b). Mathematical Characterization and Graphical Presentation of the Stiffness-Temperature-Moisture Relationship of Gliadin. Biotechnology Progress, Vol. 10, pp. 652-654.

Perdon, A.; Siebenmorgan, T.J. \& Mauronmoustakos, A. (2000). Glassy State Transition and Rice Drying: Development of a Brown Rice State Diagram. Cereal Chemistry, Vol.77, No.6, pp. 708-713.

Rangaswamy, N.S. \& Nandakumar, L. (1985). Correlative Studies on Seed Coat Structure, Chemical Composition, and Impermeability in the Legume Rhynchosia minima. Botanical Gazette, Vol. 146, No.4, pp. 501-509

Reyes-Moreno, C.; Carabez-Trejo, A.; Paredes-Lopez, O. \& Ordorica-Falomir, C. (1994). Physicochemical and Structural Properties of Two Bean Varieties which Differ in Cooking Time and the HTC Characteristic. Lebensm-Wiss. u-Technol. Vol.27, pp. 331-336.

Rhaman, M.S. (2006). State Diagram of Foods: Its Potential use in Food Processing and Product Stability. Trends in Food Science and Technology, Vol. 17, pp. 129-141.

Richman, D. \& Long, F.A. (1960). Measurement of Concentration Gradients for Diffusion of Vapors in Polymers. Journal of the American Chemical Society, Vol. 82, pp. 509-513.

Roos, Y. \& Karel, M. (1991). Plasticizing Effect of Water on Thermal Behavior and Crystallization of Amorphous Food Models. Journal of Food Science and Technology, Vol. 56, pp. 38-43.

Roos, Y.H. (1993). Water Activity and Physical State Effects on Amorphous Food Stability. Journal of Food Processing and Preservation, Vol.16, No.6, pp. 433-47.

Roos, Y.H. (1995). Phase Transitions in Foods. Academic Press, San Diego, USA, 360 p.

Roos, Y.H. (2010) Glass Transition Temperature and its Relevance in Food Processing. Annual Review of Food Science and Technology, Vol.1, pp. 469-496.

Ross, K.A.; Arntfield, S.D.; Beta, T.; Cenkowski, S. \& Fulcher, R.G. (2008). Understanding and Modifying Water Uptake Of Seed Coats Through Characterizing the Glass Transition. International Journal of Food Properties, Vol.11, No3, pp. 544-560.

Ross, K.A.; Zhang, L. \& Arntfield, S.D. (2010a). Understanding Water Uptake from Changes Induced During Processing: Chemistry of Pinto and Navy Bean Seed Coats. International Journal of Food Properties, Vol.13, No.3, pp. 631-647.

Ross, K.A.; Arntfield, S.D.; Cenkowski, S. \& Fulcher, R.G. (2010b). Relating Mechanical Changes at the Glass Transition with Water Absorption Behavior of Dry Legume Seeds. International Journal of Food Engineering, Vol.6, No.4, Article 13, pp. 1-22.

Ross, K.A.; Alejo-Lucas, D.; Malcolmson, L.J.; Arntfield, S.D. \& Cenkowski, S. (2010c). Effect of Milling Treatments and Storage Conditions on the Dehulling Characteristics of Red Lentils. International Journal of Postharvest Technology and. Innovation, Vol.2, No.1, pp. 89113.

Saskatchewan Government, 2007. Crops - Overview: Red Lentil. [Online]. Available at: http:/ / www.agriculture.gov.sk.ca/Default.aspx?DN=a88f57f0-242b-40f6-87551 fc6df4dfa14 [accessed on 31 March 2012]

Schreiber, L. \& Schonherr, J. (1990). Phase Transitions and Thermal Expansion Coefficients of Plant Cuticles. The Effects of Temperature on Structure and Function. Planta. Vol. 182, pp. 186-193. 
Sefa-Dedeh, S. \& Stanley, D.W. (1979). The Relationship of Microstructure of Cowpeas to Water Absorption and Dehulling Properties. Cereal Chemistry, Vol.56, No.4, pp. 379-386.

Seyhan-Gurtas, F.; Ak, M.M. \& Evranuz, E.O. (2001). Water Diffusion Coefficients of Selected Legumes Grown in Turkey as Affected by Temperature and Variety. Turkish Journal of Agriculture and Forestry, Vol.25, pp. 297-304.

Shao, S.; Meyer, C.J.; Ma, F.; Peterson, C.A. \& Bernards, M.A. (2007). The Outermost Cuticle of Soybean Seeds: Chemical Composition and Function During Imbibition. Journal of Experimental Botany, Vol. 58, No.5, pp. 1071-1082.

Siebenmorgen, T.J.; Yang, W. \& Sun, Z. (2004). Glass Transition Temperature of Rice Kernels Determined by Dynamic Mechanical Thermal Analysis. Transactions of the ASAE, Vol. 47, No.3, pp. 835-839.

Sievwright, C.A. \& Shipe, W.F. (1986). Effect of Storage Conditions and Chemical Treatments on Firmness, In Vitro Protein Digestibility, Condensed Tannins, Phytic Acid And Divalent Cations of Cooked Black Beans (Phaseolus vulgaris). Journal of Food Science, Vol. 51, No.4, pp. 982-987.

Slade, L. \& Levine, H. (1991). Beyond Water Activity: Recent Advances Based on an Alternative Approach to the Assessment of Food Quality and Safety. Critical Reviews in Food Science and Nutrition, Vol.30, pp. 115-360.

Sopade, P.A. \& Obekpa, J.A. (1990). Modelling Water Absorption in Soybean, Cowpea and Peanuts at Three Temperatures Using Peleg's Equation. Journal of Food Science, Vol. 55, pp. 1084-1087.

Sperling L.H. (2006). Introduction to Physical Polymer Science. $3^{\text {rd }}$ ed. Wiley, New York, 845 pp.

Tang, J.; Sokhansanj, S.; Slinkard, A.E. \& Sosulki. F (1990). Quality of Artificially Dried Lentil. Journal of Food Process Engineering, Vol.13, pp. 229-238.

Thanos, A.J. (1998). Water Changes in Canned Dry Peas and Bean During Heat Processing. International Journal of Food Science and Technology, Vol. 33, pp. 539-545.

Tiwari, B.; Gowen, A. \& McKenna, B. (2011). Introduction. In: Pulse Foods: Processing, Quality and Nutraceutical Applications, B. Tiwari, A. Gowen, B. McKenna (Eds.), 1-7, Academic Press.

Tolstoguzov, V.B. (2000). The Importance of the Glassy Biopolymer Components in Food. Nahrung Vol.44, No.2, pp. 76-84.

Vandenberg, B. \& Bruce, J. (2008). Producing Better Quality Red Lentils. PulsePoint. March, p.31-33.

Vrentas, J.S. \& Vrentas, C.M. (1991). Sorption in Glassy Polymers. Macromolecules. Vol.24, pp. 2402-2412.

Wang, N. (2005). Optimization of a Laboratory Dehulling Process for Lentil (Lens culinaris). Cereal Chemistry, Vol.82, pp. 671-676.

Watts P, (2011) Global pulse industry: state of production, consumption and trade; marketing challenges and opportunities. In: Pulse Foods: Processing, Quality and Nutraceutical Applications, B. Tiwari, A. Gowen, B. McKenna (Eds.), 437-464, Academic Press. 
Williams, R.J. (1994). Methods for Determination of Glass Transitions in Seeds. Annals of Botany, Vol.74, pp. 525-530.

Wood JA, Malcolmson LJ (2011) Pulse Milling Technologies. In: Pulse Foods: Processing, Quality and Nutraceutical Applications, B. Tiwari, A. Gowen, B. McKenna (Eds.), 193-221, Academic Press.

Zeng, L.W.; Cocks, P.S.; Kailis, S.G. \& Kuo, J. (2005). The Role of Fractures and Lipids in the Seed Coat in the Loss of Hardseededness of Six Mediterranean Legume Species. Journal of Agricultural Science, Vol.143, pp. 43-55. 